\title{
Serendipita Fungi Modulate the Switchgrass Root Transcriptome to Circumvent Host Defenses and Establish a Symbiotic Relationship
}

\author{
Prasun Ray, ${ }^{1}$ Yingqing Guo, ${ }^{1}$ Myoung-Hwan Chi, ${ }^{1}$ Nick Krom, ${ }^{1}$ Clarissa Boschiero, ${ }^{1}$ Bonnie Watson, ${ }^{1}$ \\ David Huhman, ${ }^{1}$ Patrick Zhao, ${ }^{1}$ Vasanth R Singan, ${ }^{2}$ Erika A. Lindquist, ${ }^{2}$ Juying Yan, ${ }^{2}$ Catherine Adam, ${ }^{2}$ \\ and Kelly D. Craven ${ }^{1, \dagger}$ \\ ${ }^{1}$ Noble Research Institute, LLC, Ardmore, OK 73401, U.S.A. \\ ${ }^{2}$ United States Department of Energy Joint Genome Institute, Walnut Creek, CA, U.S.A.
}

Accepted 13 July 2021.

\begin{abstract}
The fungal family Serendipitaceae encompasses root-associated lineages with endophytic, ericoid, orchid, and ectomycorrhizal lifestyles. Switchgrass is an important bioenergy crop for cellulosic ethanol production owing to high biomass production on marginal soils otherwise unfit for food crop cultivation. The aim of this study was to investigate the host plant responses to Serendipita spp. colonization by characterizing the switchgrass root transcriptome during different stages of symbiosis in vitro. For this, we included a native switchgrass strain, Serendipita bescii, and a related strain, $S$. vermifera, isolated from Australian orchids. Serendipita colonization progresses from thin hyphae that grow between root cells to, finally, the production of large, bulbous hyphae that fill root cells during the later stages of colonization. We report that switchgrass seems to perceive both fungi prior to physical contact, leading to the activation of chemical and structural defense responses and putative host disease resistance genes. Subsequently, the host defense system appears to be quenched and carbohydrate metabolism adjusted, potentially to accommodate the fungal symbiont. In addition, prior to contact, switchgrass exhibited significant increases in root hair density and root surface area. Furthermore, genes involved in phytohormone metabolism such as gibberellin, jasmonic acid, and salicylic acid were activated during different stages of colonization. Both fungal strains induced plant gene expression in a similar manner, indicating a conserved plant response to members of this fungal order. Understanding plant responsiveness to Serendipita spp. will inform our efforts to integrate them into forages and row crops for optimal plant-microbe functioning, thus facilitating low-input, sustainable agricultural practices.
\end{abstract}

${ }^{\dagger}$ Corresponding author: K. D. Craven; kdcraven@noble.org

Funding: This work was funded by The BioEnergy Science Center and The Center for Bioenergy Innovation, both a United States Department of Energy Research Center supported by the Office of Biological and Environmental Research in the United States Department of Energy Office of Science (grant DE-AC02-05CH11231)

*The $\boldsymbol{e}$-Xtra logo stands for "electronic extra" and indicates that supplementary figures and supplementary tables are published online.

The author(s) declare no conflict of interest. distributed under the CC BY-NC-ND 4.0 International license.
Keywords: endophytes, fungus-plant interactions, host defense, mycorrhiza, mycorrhizal interactions, phytohormone, plant antifungal responses, plant genes and cellular responses, root endophyte, Serendipitaceae

Switchgrass (Panicum virgatum L.) has been identified as an important bioenergy crop for cellulosic ethanol production in the United States (McLaughlin and Adams Kszos 2005). It is a productive, perennial $\mathrm{C} 4$ species native to the United States with a broad cultivation range. Switchgrass has great potential in Oklahoma, because of its sustainable high biomass production on marginal soil that cannot be used for food crop cultivation. Field studies have demonstrated that switchgrass grown and managed as a biomass crop produces $540 \%$ more renewable energy than the energy consumed in its production, and has other significant environmental benefits, including a deep root system that adds carbon to the soil and can stabilize the soil matrix (Schmer et al. 2008). The United States Department of Energy and United States Department of Agriculture have set a goal of replacing $30 \%$ of current petroleum consumption with biofuels by 2030 (Perlack 2005). Meeting this mandate will require approximately 1 billion dry tons of biomass feedstock per year. We can move toward achieving this ambitious goal with relatively modest changes in land use and agronomic practices such as the utilization of plant-growth-promoting microbes, wherein the microbial partner can enhance plant fitness and productivity and often reduce pathogenic infection (Begum et al. 2018; Ghimire et al. 2009; Kim et al. 2012).

Fungi in the family Serendipitaceae (Oberwinkler et al. 2014) interact with plant roots in diverse ways, forming mycorrhizae of nearly every known type, and as asymptomatic endophytes (Weiß et al. 2016). These associations also appear to be widespread, detected from the roots of plants growing on every continent, including Antarctica, and from all major plant families, including ancient lineages such as the Jungermannoids (Weiß et al. 2011). Infection by these fungi is also common in members of the Ericaceae plant family, which thrive in harsh soils with low $\mathrm{pH}$ and the majority of nutrients tied up in soil organic matter (Selosse et al. 2007). However, despite the prevalence of Serendipita fungi and the diversity of lifestyles they forge with their plant hosts, we know very little regarding signaling between the partners, prior to both the formation of the symbiosis and subsequent establishment of symbiotic functionality.

Phylogeny suggests that members of Serendipitaceae emerged from saprobes, including brown rot and white rot species, and it 
has been proposed that they have transitioned from feeding on dead or decaying plant tissues to endophytism or to one of several types of mycorrhizae, all within one fungal order (Kohler et al. 2015; Lahrmann et al. 2013; Weiß et al. 2016). Perhaps as a reflection of their ancestry, all three types of mycorrhizae listed above involve bidirectional fluxes of carbon between host and fungal symbiont, suggesting that Serendipitaceae fungi can obtain nutrients, including carbon, from soil organic matter (SOM). Furthermore, access to this SOM pool could imply that these fungi are not solely dependent upon host-derived carbon, a considerable cost associated with arbuscular mycorrhizae (Wipf et al. 2019).

We have isolated the first North American strain of Serendipita, Serendipita vermifera subsp. bescii NFPB0129 (hereafter referred to as $S$. bescii), from the roots of a switchgrass plant collected from the prairies of northern Oklahoma (Craven and Ray 2017; Ray et al. 2018a). Using greenhouse and field trials, we have clearly demonstrated the ability of Serendipita fungi to enhance seed germination, biomass production, and drought tolerance in switchgrass (Ghimire and Craven 2011; Ray et al. 2015), and modulate the nutrient starvation response in winter wheat (Triticum aestivum L.) (Ray et al. 2021).

Here, we sought to characterize the transcriptome of switchgrass roots colonized with either $S$. vermifera or $S$. bescii at different stages of the symbiosis (Fig. 1). The primary objective of the study was to define host gene expression in response to Serendipita colonization using switchgrass as a model. Strains from North America and Australia were compared, enabling a crude cross-taxa comparison. These data allowed us to understand not only the recognition and colonization process from the host perspective but also some mechanisms underlying plant growth promotion in response to fungal colonization.

\section{RESULTS}

Progression of Serendipita symbiosis is manifested by intracellular colonization.

Progressing colonization of switchgrass root cells by $S$. bescii and $S$. vermifera is shown in Figure 2. Initial colonization is marked by sparse intracellular growth of fungal hyphae (Fig. 2A). This is followed by the development of dense hyphal coils that fill the intracellular space of colonized cells during the

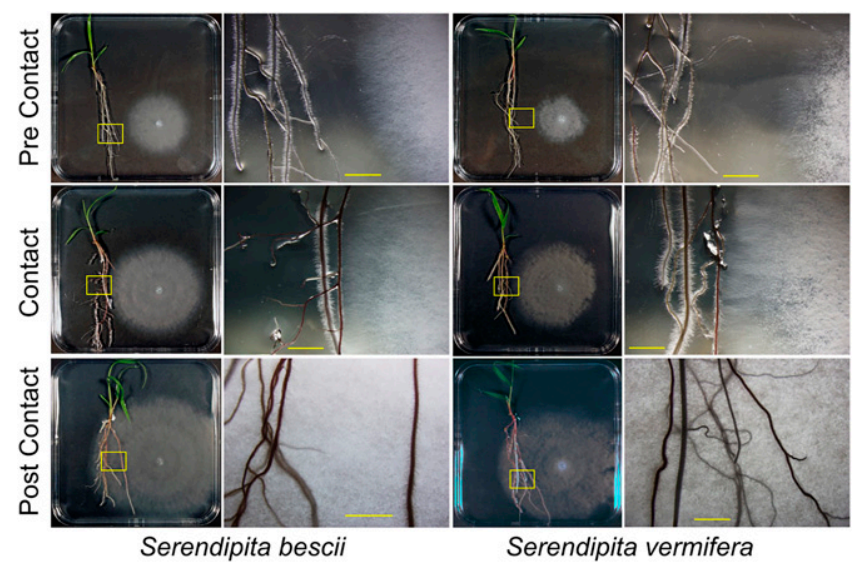

Fig. 1. Layout of the experiment for transcriptome analysis. Plates were inoculated by placing a drop of fungal inoculum approximately $5 \mathrm{~cm}$ away from the seedling. In this study, precontact stage is defined as the time point when the periphery of the fungal colony is approximately 1 $\mathrm{cm}$ away from the roots, contact when the fungal colony is just touching the roots, and postcontact when the fungal colony has completely covered the root. For each of these stages, the yellow-boxed area is enlarged to highlight detail. Scale bar on enlarged image $=1 \mathrm{~cm}$ postcontact stage (Fig. 2B). These structures resemble the hyphal coils formed by some ericoid mycorrhiza inside the colonized root cells of ericaceous plants (Vohník et al. 2012). Importantly, fungi in the Serendipitaceae family are common mycorrhizal symbionts of ericoid plants. The late postcontact stage of Serendipita colonization was manifested by cortical root cells completely packed with aggregates of swollen, moniloid fungal hyphae (Fig. 2C), which are also observed in other Serendipita strains (Riess et al. 2014; Warcup and Talbot 1967).

To complement our confocal microscopy results, we quantified the relative abundance of fungal biomass in planta by quantitative reverse-transcription (qRT)-PCR (Supplementary Fig. S4). As expected, percent colonization was undetermined $(<0.02 \%)$ at precontact and contact stages of colonization. Percent colonization was at its peak (263\% for S. bescii and $608 \%$ for $S$. vermifera) during the postcontact stage of colonization and then receded (19\% for S. bescii and $12 \%$ for $S$. vermifera) at the late postcontact stage, perhaps due to an increased switchgrass root/fungal biomass ratio compared with the postcontact stage of colonization.

\section{Serendipita fungi enhanced root hair density and surface area preceding colonization and shoot biomass following colonization.}

Both $S$. bescii and $S$. vermifera significantly increased root hair density and surface area prior to switchgrass colonization compared with uninoculated controls (Fig. 3A). Root hair density increased by 74 and $112 \%$ (Fig. 3B) and estimated root surface area by 76 and $125 \%$ (Fig. 3C) when colonized with $S$. bescii and $S$. vermifera, respectively.

Effects of $S$. bescii and $S$. vermifera colonization on shoot growth of switchgrass 7 weeks postcolonization are shown in Figure 4A. Both $S$. bescii and $S$. vermifera significantly increased shoot height (Fig. 4B) and biomass (Fig. 4C) with respect to uninoculated plants. Shoot height increased by 19 and

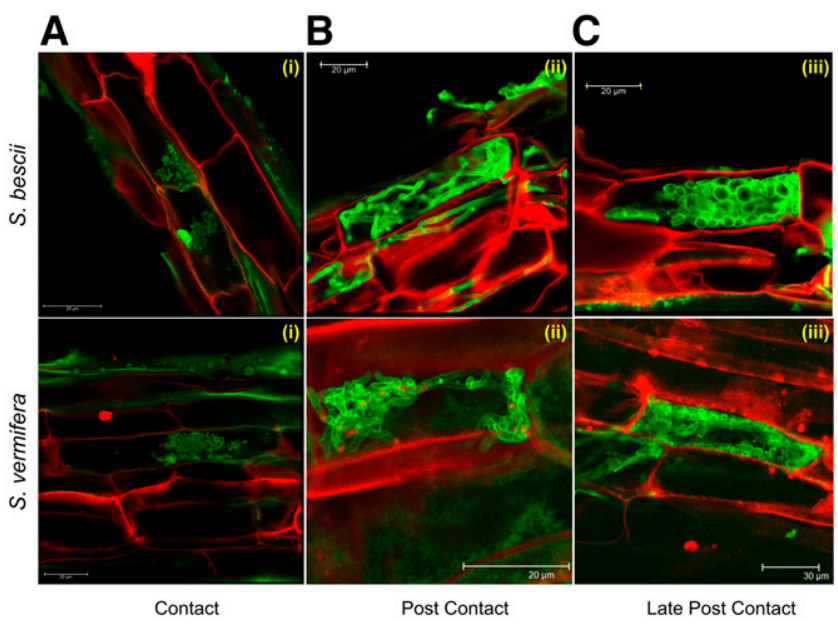

Fig. 2. Progression of Serendipita bescii and S. vermifera colonization in switchgrass roots by confocal microscopy. A, Colonization in the contact stage is marked by sparse intracellular growth of fungal hyphae. This was followed by $\mathbf{B}$, the development of dense hyphal coils at the postcontact stage and, ultimately, C, cortical cells completely packed with aggregates of swollen, moniloid fungal hyphae at late postcontact stage. Fungal hyphae stained with WGA-AF 488 were excited using 488-nm of the white light laser (WLL), and emission was detected at 493 to 535 $\mathrm{nm}$. Plant cell walls stained with propidium iodide (PI) were visualized by exciting at $538 \mathrm{~nm}$ by WLL, and emission was detected at 592 to $650 \mathrm{~nm}$. Sequential scanning between lines was used to detect WGA-AF 488 emission from fungal hyphae and PI from plant cell walls. Images were captured using the Leica TCS-SP8 running LAS X software (Leica Microsystems, Wetzlar, Germany), and images from these channels were overlaid to show fungal colonization in plant cells. 
$17 \%$ and biomass increased by 40 and $28 \%$ when colonized with $S$. bescii and $S$. vermifera, respectively. However, no significant increase in tiller diameter (Fig. 4D) was recorded due to fungal colonization.

\section{Network analysis, distribution, and functional} categorization of differentially expressed genes.

Analysis of the switchgrass root transcriptome revealed 208 genes that were differentially expressed due to $S$. bescii and $S$. vermifera colonization at different stages of symbiosis (Fig. 5) which constitutes only $0.2 \%$ of the switchgrass genome. This finding suggests that Serendipita spp. only slightly modulate the switchgrass root transcriptome to accommodate the fungal symbiont, as opposed to arbuscular mycorrhiza or pathogenic fungi, both of which extensively reprogram the host transcriptome for establishment of either a beneficial or detrimental relationship with their host (Bonfante and Genre 2010; Sarkar et al. 2019).
Network analysis of all eight sets of differentially expressed genes (DEGs) based on their expression profile is shown in Figure 5A and the allocation of DEGs is shown in Figure 5B. Interestingly, differentially expressed plant genes due to $S$. bescii or $S$. vermifera colonization were tightly clustered in a stagedependent manner (Fig. 5A). The number of genes and their pattern of expression at each stage of colonization was also similar when colonized with either S. bescii or S. vermifera (Fig. 5B; Supplementary Table S1). Hierarchical clustering and gene ontology (GO) enrichment analysis of all 208 differentially expressed switchgrass genes is shown in Figure 6A and B. As above, the DEGs from both fungi followed a similar clustering pattern within the four individual stages of colonization investigated in this study (Fig. 6A).

The global GO enrichment analysis (Fig. 6B) revealed that cellular aromatic compound metabolic processes (29\%), oxidoreductase activity (21\%), and endopeptidase activity $(18 \%)$ were
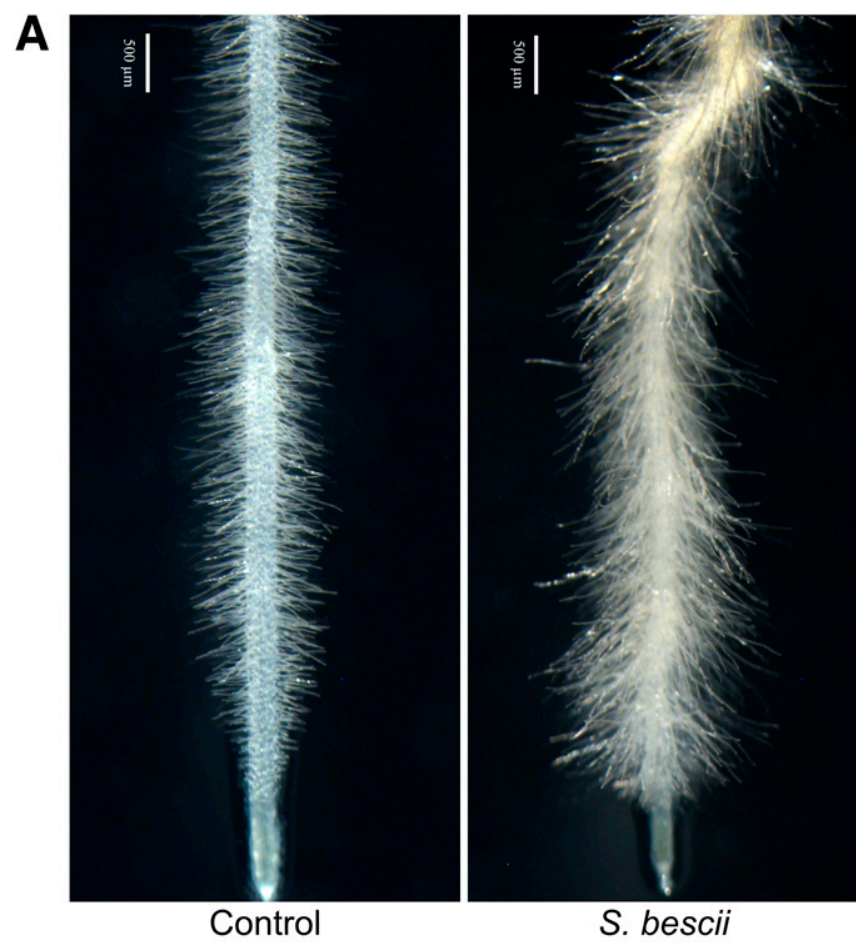

S. bescii

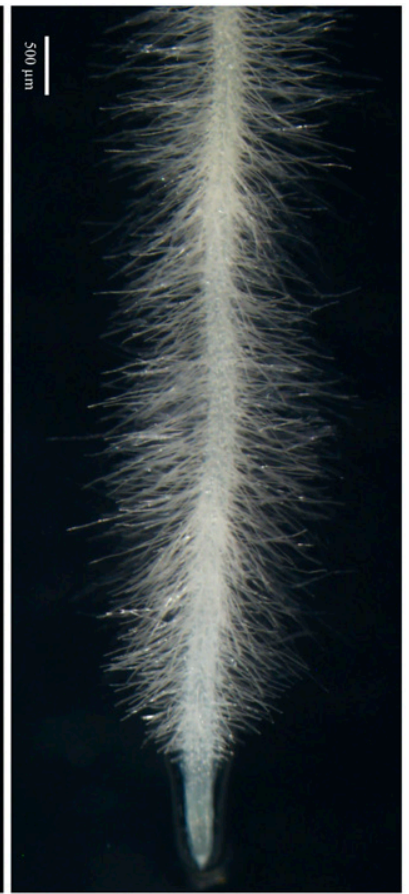

S. vermifera

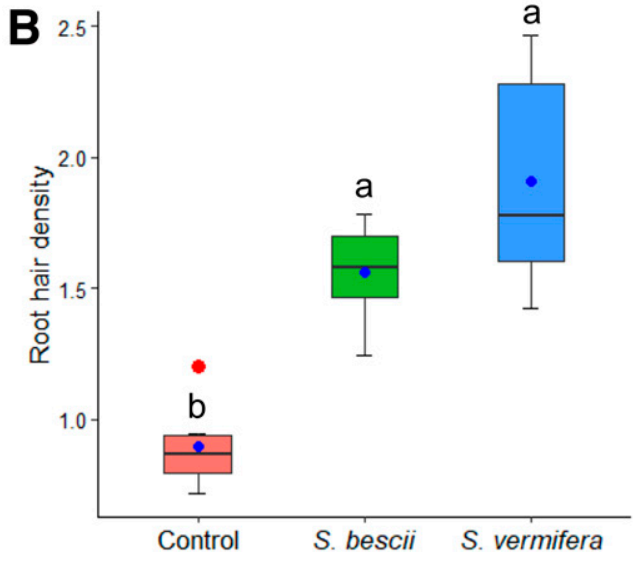

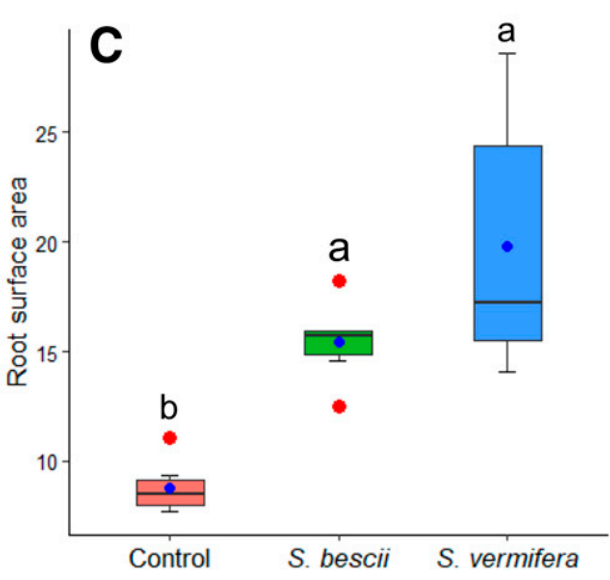

Fig. 3. Visualization and quantification of switchgrass root hair density and surface area the precontact stage of Serendipita bescii and S. vermifera colonization. A, Images of the root tip were acquired using stereomicroscope. Scale bar $=500 \mu \mathrm{m}$. B, Root hair density and $\mathbf{C}$, root surface area increased significantly in comparison with uninoculated plants. Within each colonization treatment, the data were analyzed by one-way analysis of variance using CoStat statistical software 6.4 (Cohort Berkeley, CA, U.S.A.). Treatment means were compared using the least significant difference value at $P<0.05$. Blue dots denote mean values of six biological replicate data points. Boxes with different letters denote significant difference between treatments at $P<0.05$. 
the top three GO terms that functionally categorize approximately $70 \%$ of all genes that were differentially expressed due to Serendipita colonization. The remaining $30 \%$ comprised genes that are distributed into various $\mathrm{GO}$ categories such as ADP binding, nucleic acid binding, hydrolase activity, carbohydrate metabolism, and so on, all essential for various fundamental plant processes.

\section{Kyoto Encyclopedia of Genes and Genomes} enrichment analysis of DEGs.

Differentially expressed switchgrass genes due to $S$. bescii or $S$. vermifera colonization at the different stages of symbiosis were functionally categorized by Kyoto Encyclopedia of Genes and Genomes (KEGG) pathway enrichment analysis. We identified 20 and 22 KEGG pathways that were enriched due to $S$. bescii or S. vermifera colonization, respectively (Fig. 7A and B) according to Fisher's exact test at false discovery rate (FDR)corrected $P$ value $<0.05$. Although the majority of the pathways were enriched in specific stages of colonization, two pathways (namely, biosynthesis of secondary metabolites and diterpenoid biosynthesis due to $S$. vermifera) and four pathways (namely, carbon fixation in photosynthetic organisms, carbon metabolism, diterpenoid biosynthesis, and plant-pathogen interaction due to $S$. bescii) were significantly enriched at multiple stages of colonization (Fig. 7; Supplementary Table S2).

\section{Serendipita transiently circumvents host defense to establish the symbiotic relationship.}

Chemical defense. Plants perceive the presence of microbes through recognition of microbe-derived compounds even before establishment of physical contact, eventually leading to the activation of plant defense genes (Cook et al. 2015; Fesel and Zuccaro 2016a). This host response is often then muted in the presence of beneficial microbes. In the present study, prior to physical contact, we observed several plant defense genes that were upregulated due to both $S$. bescii and $S$. vermifera colonization (Supplementary Table S3). In particular, we found three genes (Pavir.8NG101200, Pavir.J719400, and Pavir.5NG225300) involved in biosynthesis of the antifungal phytoalexin that were highly induced during the precontact stage of colonization (Table 1).

Monoterpenes are a class of isoprenoids that are often involved in plant defense response against from herbivores and pathogens (Singh and Sharma 2015; Turner and Croteau 2004). In our study, three genes (Pavir.1KG410000, Pavir.1KG410100,

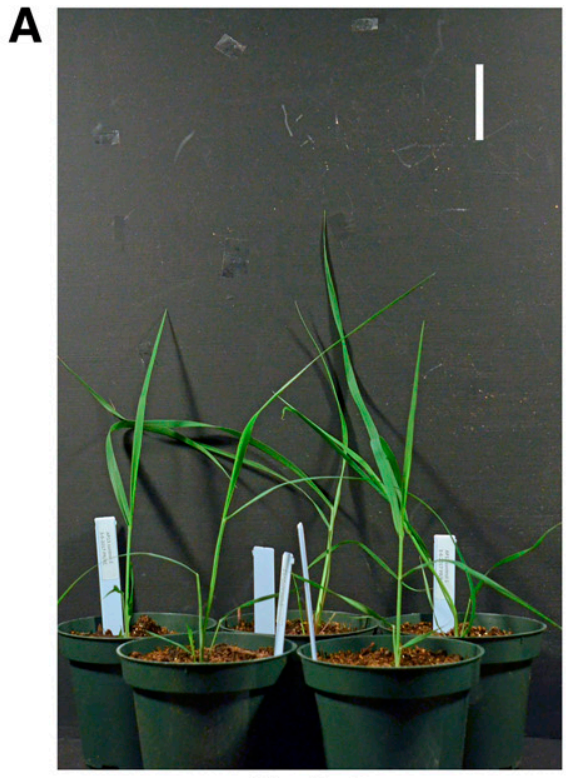

Control

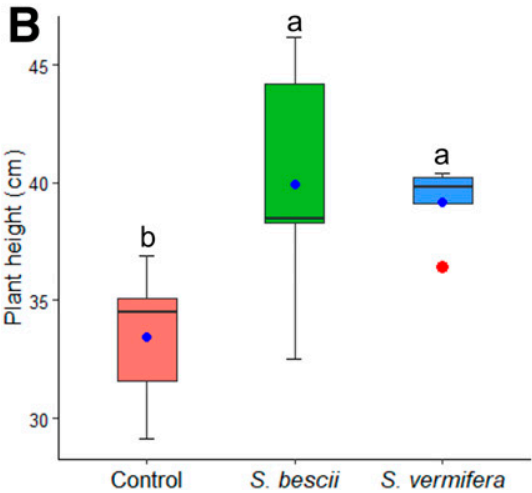

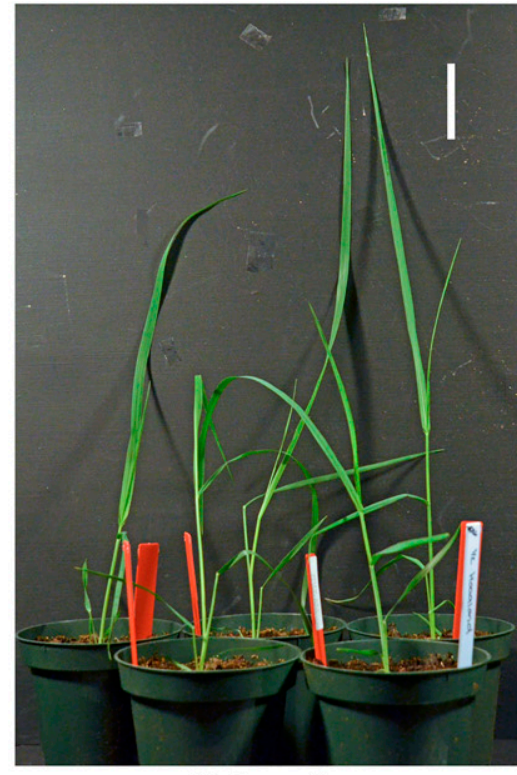

S. bescii

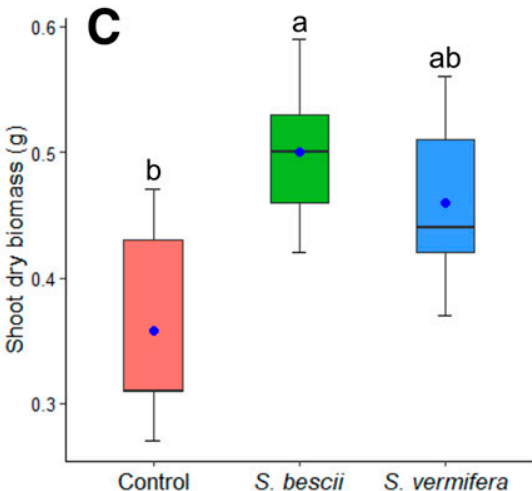

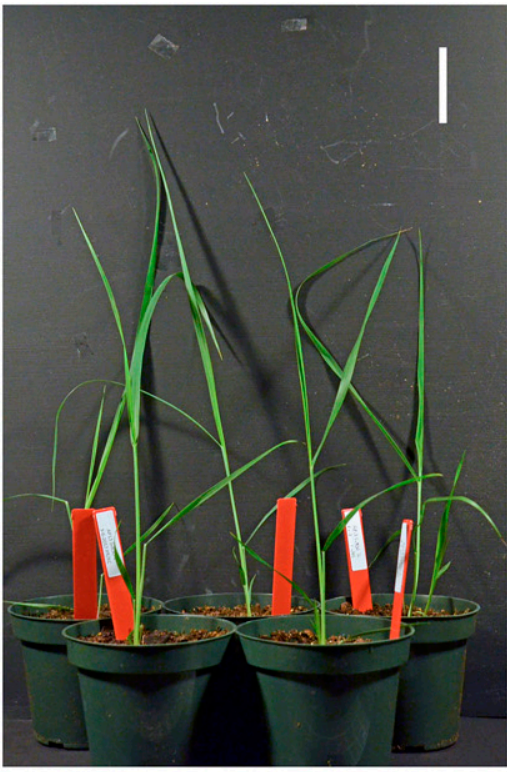

S. vermifera

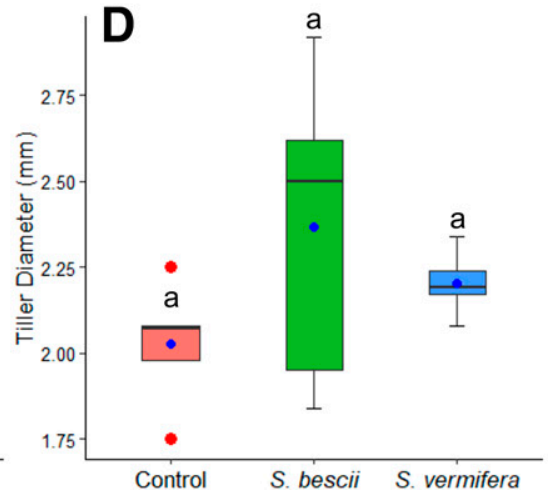

Fig. 4. Effect of Serendipita bescii and S. vermifera colonization on A, overall plant growth; B, plant height; C, shoot dry biomass; and $\mathbf{D}$, tiller diameter of switchgrass at late postcontact stage of colonization. Plant height (B) increased significantly when colonized with $S$. bescii and $S$. vermifera and dry biomass (C) increased significantly when colonized with S. bescii in comparison with uninoculated plants. No significant increase in tiller diameter (D) was recorded due to colonization by either fungus. Within each colonization treatment, the data were analyzed by one-way analysis of variance using CoStat statistical software 6.4 (Cohort Berkeley, CA, U.S.A.). Blue dots denote mean values of five biological replicate data points. Boxes with different letters denote significant difference between treatments at $P<0.05$. Differences between means that share a letter are not statistically significant. 
and Pavir.1KG410200) putatively involved in monoterpenoid biosynthesis were found to be downregulated at the postcontact stage due to $S$. bescii and $S$. vermifera colonization (Table 1).

Plant glutathione S-transferases (GSTs) are multifunctional enzymes known to be induced upon microbial infection (Gullner et al. 2018). We found genes encoding GSTs to be induced prior to physical contact with the fungal symbiont (Pavir.6NG319800) and eventually repressed (Pavir.9NG495700 and Pavir.9NG495800) after colonization (i.e., the postcontact stage) (Table 1).

Structural defense. Lignification is a developmental process that plants engage in to fortify their cell walls, and can contribute to disease resistance from pathogens (Vance et al.
1980). Here, we found one laccase gene (Pavir.1NG327600), putatively involved in cell wall lignification (Zhang et al. 2019), to be upregulated prior to physical contact. In contrast, we identified a Shikimate O-hydroxycinnamoyltransferase gene (Pavir.2NG224400), also involved in the lignin biosynthesis pathway (Sun et al. 2018), to be downregulated at the postcontact stage due to $S$. bescii and $S$. vermifera colonization (Table 1). Like lignin, cuticular wax often acts as a barrier against biotrophic fungi during the prepenetration stage of infection (Inada and Savory 2011). We found a gene encoding a wax2 domaincontaining protein (Pavir.1NG353200), involved in cuticle membrane and wax biosynthesis, to be downregulated at contact and

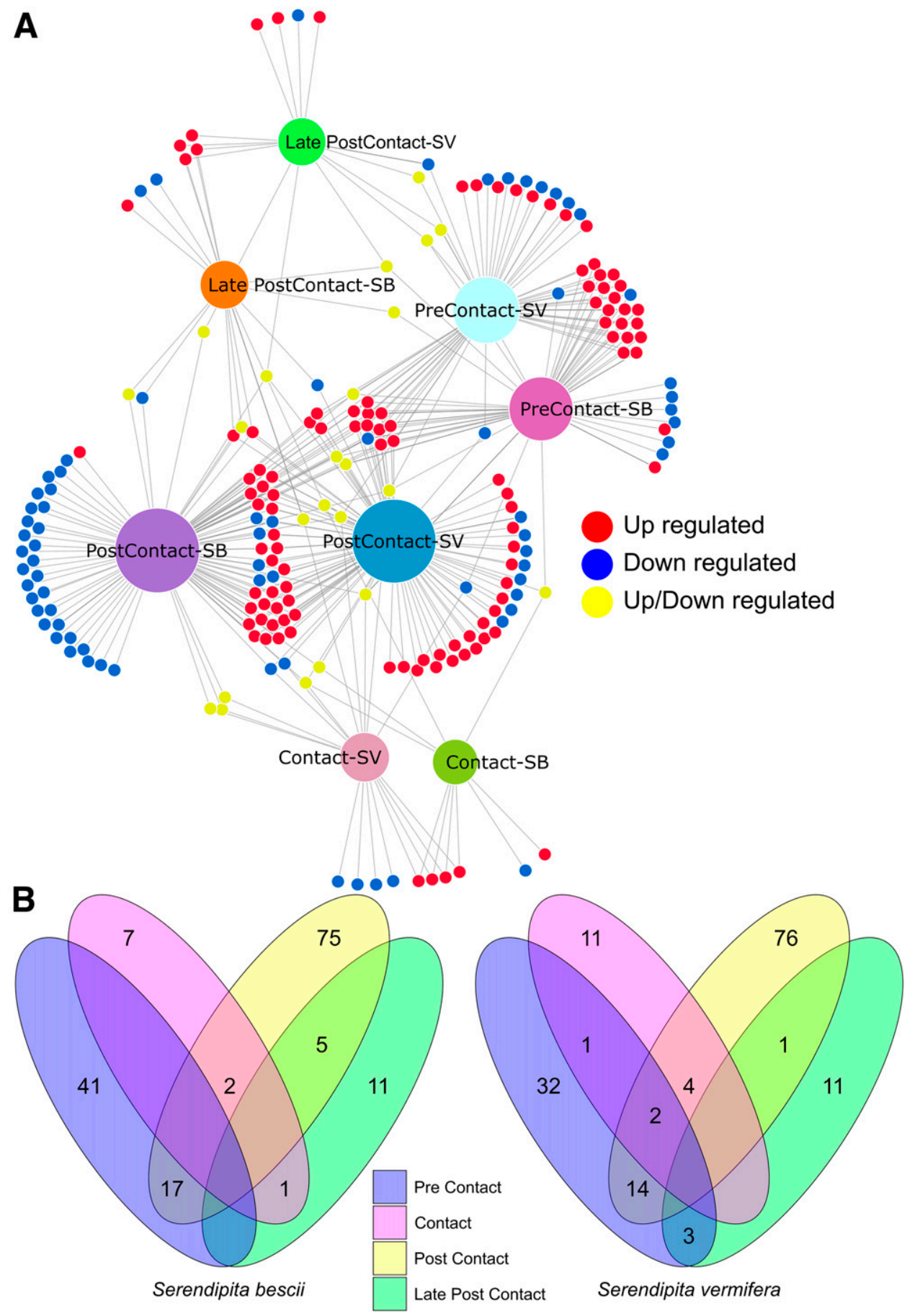

Fig. 5. A, Network analysis of differentially expressed switchgrass genes due to Serendipita bescii (SB) and S. vermifera (SV)vat four different stages of colonization. Red and blue nodes denote upregulated and downregulated genes, respectively. Yellow nodes denote upregulation in one condition but downregulation in the other. B, Venn diagram showing the numbers and overlap of differentially expressed genes used for the network analysis. 
postcontact stages of colonization. Although roots do not typically contain cutin but, rather, the structurally related compound suberin, it has been recently reported that arbuscular mycorrhizal (AM) fungi can perceive cutin monomers as a signal (Murray et al. 2013; Wang et al. 2012).

Host disease resistance. In this study, we found that Serendipita colonization activated 11 leucine-rich repeat and nucleotide-binding adaptor shared by APAF-1, resistance (R) proteins, and CED-4 domain-containing disease resistance $(R)$ genes at different stages of colonization (Supplementary Table S3). Of these, two genes putatively involved in stripe rust resistance (Pavir.8KG325100 and Pavir.8NG336400) were downregulated at the precontact stage of colonization when either of the fungal symbionts were present (Table 1). Interestingly, most of these $R$ genes were upregulated at subsequent contact
(Pavir.J509800 and Pavir.8NG213200), postcontact (Pavir.7KG240500 and Pavir.7NG351300), and late postcontact (Pavir.8NG064700) stages when colonized with $S$. bescii and $S$. vermifera respectively (Supplementary Table S3).

\section{Serendipita induces genes involved}

in phytohormone and defense signaling.

Salicylic acid (SA)-mediated defense signaling often leads to activation of the pathogenesis-related (PR) protein 1, resulting in systemic acquired resistance (Ali et al. 2018). We identified three PR1 genes (Pavir.6KG259000, Pavir.6KG213100, and Pavir.6KG260300) that were highly upregulated at the precontact stage due to $S$. bescii colonization (Table 1). In addition, three genes (Pavir.9KG616700, Pavir.9NG796100, and Pavir.9KG268100) encoding jasmonate ZIM-domain (JAZ)

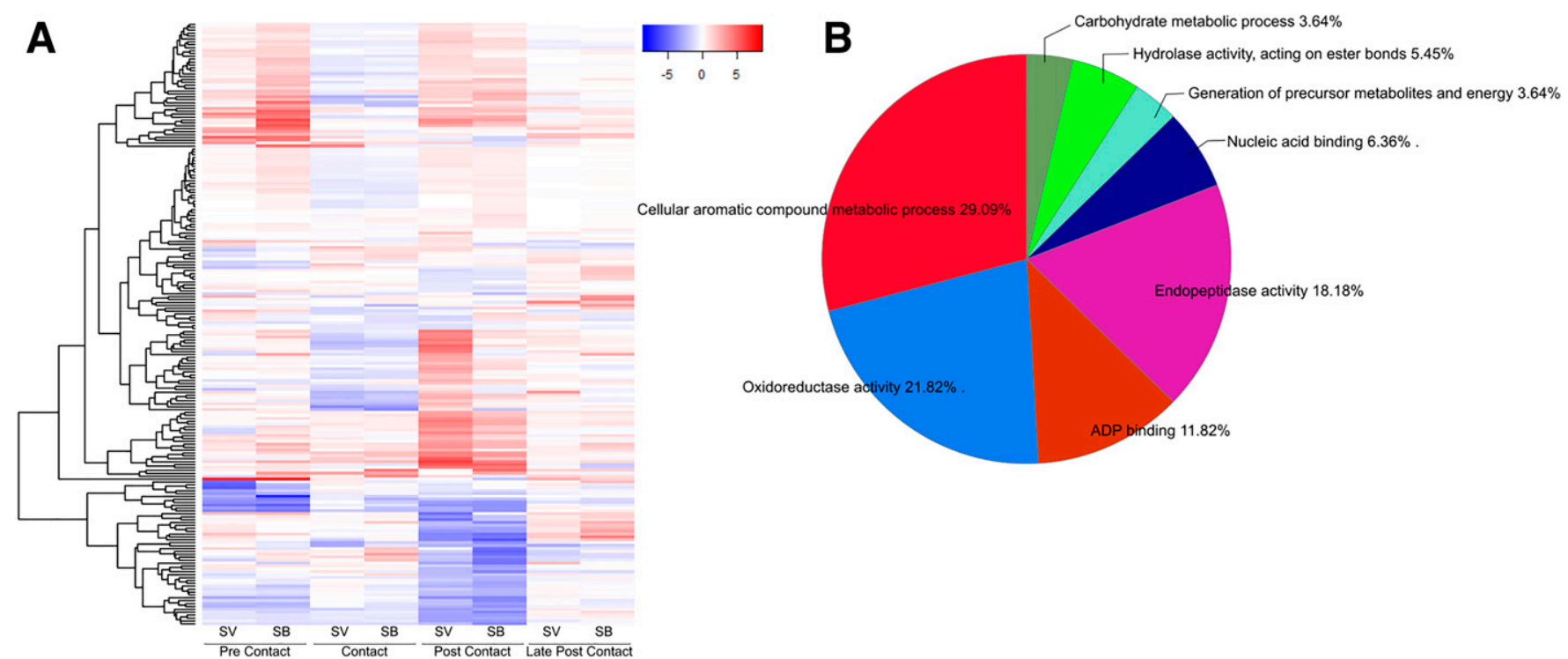

Fig. 6. A, Hierarchical clustering heat map of differentially expressed genes in switchgrass at four different stages of colonization due to Serendipita bescii (SB) and S. vermifera (SV). Signal ratios are shown in a red-blue color scale, where red represents upregulation and blue represents downregulation. Each columns represents $\log _{2}$ fold-change value and each row represents a differentially expressed gene. Hierarchical clustering between all of the differentially expressed genes is shown on the left tree. B, Gene ontology enrichment analysis of all 208 differentially expressed switchgrass genes.
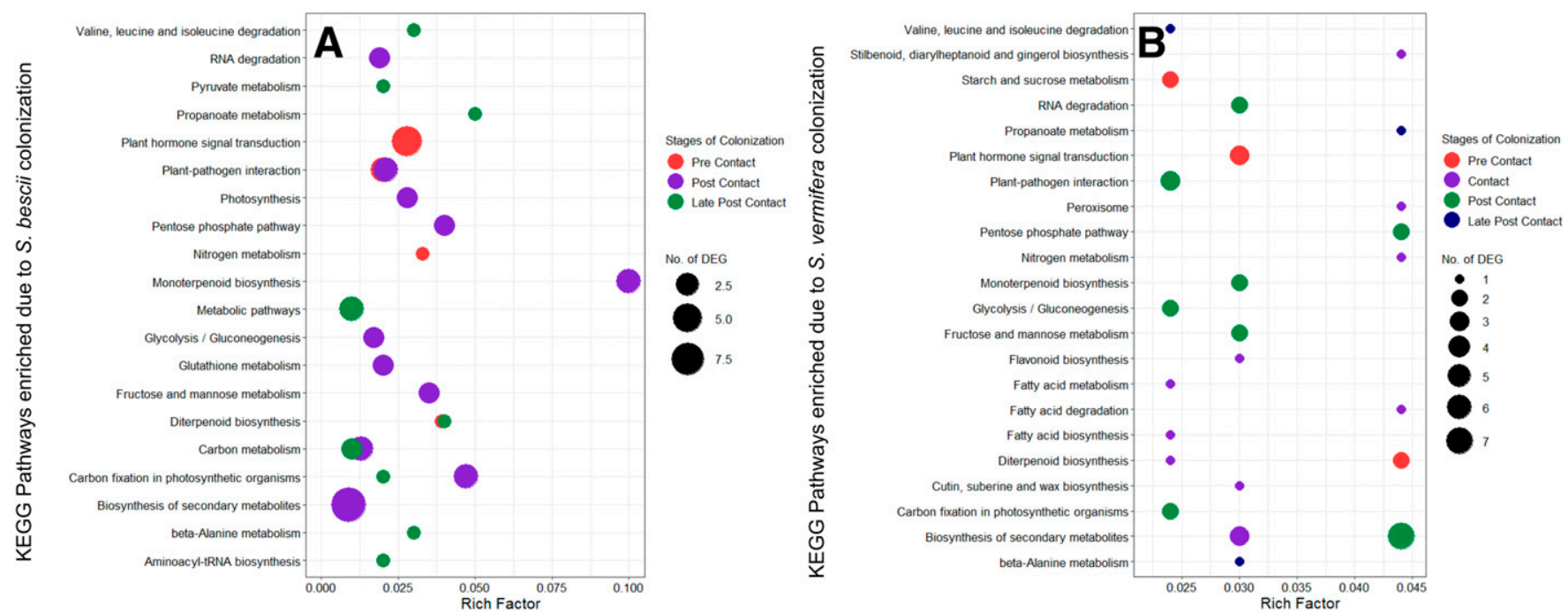

Fig. 7. Scatter plot of the enriched Kyoto Encyclopedia of Genes and Genomes (KEGG) pathways at four different stages of colonization due to A, Serendipita bescii and $\mathbf{B}, S$. vermifera. The rich factor is the ratio of the number of differentially expressed genes to the total gene number in a certain pathway. The rich factor value is directly proportional to the degree of enrichment. The color and size of the dots represent stages of colonization, and the number of differentially expressed genes mapped to the indicated pathways. In all, 20 and 22 pathways that were enriched due to $S$. bescii or $S$. vermifera colonization, respectively, according to Fisher's exact test at false discovery rate-corrected $P$ value $<0.05$ are shown. 
proteins and involved in the negative regulation of jasmonic acid (JA) signaling were upregulated prior to physical contact with either S. bescii and S. vermifera (Table 1). To elucidate the role of SA and JA signaling in switchgrass colonized with either $S$. vermifera or $S$. bescii, we quantified levels of plant SA and JA at both the precontact and postcontact stages of colonization. Although we observed increased levels of SA and decreased levels of JA at both stages of $S$. bescii or $S$. vermifera colonization, the results were not always statistically significant (Supplementary Fig. S3).

Hormonal cross talk greatly influences defense responses, as exemplified by gibberellins (GA), which modulate the SA-JA balance. In this study, we found two putative GA2ox genes (Pavir.7NG327800 and Pavir.1KG391400) that mediate deactivation of bioactive GA (Yamaguchi 2008) to be downregulated at the precontact stage but upregulated at the postcontact stage of $S$. vermifera colonization. Conversely, we identified a GA biosynthesis gene, GA20ox (Pavir.6KG167600), that was downregulated at the postcontact stage of $S$. bescii colonization (Table 1).

\section{Role of plant small secreted proteins} in root colonization by Serendipita spp.

Plants have large diverse families of small secreted proteins (SSPs) that play critical roles in the processes of development, defense, stress response, symbiosis, and so on (Nakamura et al. 2012). In the present study, we found 27 SSP-encoding switchgrass genes that were differentially expressed due to Serendipita symbiosis, constituting 13\% of the total number of DEGs (Supplementary Table S4; Supplementary Fig. S1). Most genes coding for SSPs were upregulated $(78 \%)$ with putative functions in a variety of defense responses, including SA-induced and reactive oxygen species-mediated defense responses as well as biosynthesis of the antifungal phytoalexins (Supplementary Table S4).

\section{Serendipita colonization modulates expression of genes involved in host carbohydrate metabolism.}

Photosynthetically synthesized sucrose is typically transported to roots and cleaved into glucose and fructose by sucrose synthases (SUSs) and invertases. Trehalose-6-phosphate (Tre6P) acts as an important signaling metabolite that has been shown to regulate sucrose utilization in plants (Ponnu et al. 2011). We found one SUS gene (Pavir.1NG545300) that was upregulated and a Tre6P synthase gene (Pavir.6KG237100) downregulated during the precontact stage of colonization with $S$. vermifera (Table 1). Furthermore, two fructose 1,6-bisphosphatase genes (Pavir.1KG232800 and Pavir.9NG352200) involved in gluconeogenesis were found to be upregulated at the postcontact stage due to colonization by both fungi (Table 1).

\section{DISCUSSION}

Mycorrhization involves the adaptation of both host and symbiont to create novel symbiotic interfaces within root cells. In arbuscular and ectomycorrhizae, where these interfaces are defined, there are coordinated developmental programs in both partners that enable the exchange of nutrients and metabolites (Bonfante and Genre 2010; Parniske 2008). Host responses to colonization by the root endophyte $S$. indica is typically followed by positive impacts on plant performance. This particular strain of Serendipita has been extensively studied using the model plant Arabidopsis thaliana and a number of important crop species, including barley, wheat, and corn (Fesel and Zuccaro 2016b; Lahrmann et al. 2015; Serfling et al. 2007; Waller et al. 2005; Yadav et al. 2010). Still, much less is known about these unique "serendipitoid" symbioses, including events prior to root penetration such as host plant recognition, as well as downstream signaling that ultimately leads to successful host colonization in other members of the Serendipitaceae family.

\section{Root colonization.}

Colonization of switchgrass roots was manifested first by fungal hyphae growing intercellularly between root cells, followed by the formation of hyphal coils within host cells and, subsequently, bulbous hyphae at more mature stages of colonization. The percent colonization of root cells by the fungus increased over time, then declined when the plants were transferred to larger pots in a greenhouse, reasonably due to an increased switchgrass root volume/fungal biomass ratio compared with the smaller plants grown in a Petri dish in vitro. Hyphal coil-like structures are frequently observed in ericoid mycorrhizal associations involving the fungal order Sebacinales. (Vohník et al. 2016; Weiß et al. 2011). We hypothesize that, like other ericoid mycorrhizae, these coil-like structures are the site of carbon-fornutrient exchange between plants and Serendipita fungi (Giesemann et al. 2020). Furthermore, these same interfaces could well be sites for mycoheterotrophy (fungus-to-plant carbon transfer), commonly observed in mycorrhizal associations involving members of the sister family Sebacinaceae (Kennedy et al. 2011). The coils are ephemeral, and are degraded following some time as a functional plant-fungus interface (Kuga et al. 2014; Yamamoto et al. 2017). Whether these hyphal coils are, indeed, the sites for fungus-to-plant carbon transmission in a nonmycoheterotrophic plant like switchgrass is beyond the scope of the current study. We are currently investigating this hypothesis in the closely related $\mathrm{C}_{4}$ grass species $P$. hallii using ${ }^{13} \mathrm{CO}_{2}$ stable isotope probing to track carbon trading between $S$. bescii and its host plant (Hestrin et al. 2020).

\section{Serendipita colonization enriched GO categories that are fundamental for plant processes.}

The largest cluster (29\%) among all enriched GO categories, cellular aromatic compound metabolic processes, encompasses GO terms such as phosphorous metabolic processes, (GO:0006793), cellular nitrogen compound metabolic process (GO: 0034641), and regulation of cellular biosynthetic process (GO:0031326), all essential for nutrient acquisition and utilization. The oxidoreductase activity cluster that follows next, with a $21 \%$ share (Fig. 6B), consists of terpene synthase activity (GO: 0010333) involved in the biosynthesis of core components of chemical defenses against herbivores, insect pests, and microbial pathogens (Karunanithi and Zerbe 2019). Additionally, genes associated with carbohydrate metabolic processes (GO: 0005975) were enriched due to Serendipita colonization. Similar findings following $S$. indica colonization enriched GO categories involved in diterpenoid biosynthetic process (GO:0016102) and response to sucrose starvation (GO:0043617) in soybean roots (Bajaj et al. 2018), and $S$. vermifera colonization enriched $\mathrm{GO}$ categories associated with carbohydrate metabolism (GO:0005975) and cellular nitrogen compound biosynthesis processes (GO:0044271) in barley (Sarkar et al. 2019).

Endopeptidase activity represents $18 \%$ of the enriched GO categories due to Serendipita colonization in switchgrass. This cluster includes GO terms such as organonitrogen compound metabolic process (GO: 1901564), peptidase activity (GO: 0008233), and proteolysis (GO: 0006508), among others, all potentially involved in assimilation of organic nitrogen $(\mathrm{N})$ from various protein sources. Such a phenomenon has been very well documented in ectomycorrhizal fungus Paxillus involutus (Shah et al. 2013), as well as in S. vermifera and $S$. bescii under N starvation conditions in vitro (Ray et al. 2019) and in $S$. indica and $S$. vermifera in planta (Lahrmann et al. 2013; Sarkar et al. 2019). 


\section{Improved plant growth and development.}

Serendipita colonization is marked by multiple beneficial effects on a variety of host plants such as maize, poplar, tobacco, barley, wheat, and switchgrass (Ray and Craven 2016; Ray et al. 2015; Serfling et al. 2007; Sherameti et al. 2005; Varma et al. 1999; Waller et al. 2005). In agreement with our previous work demonstrating enhanced plant growth, we found significant improvements in switchgrass shoot biomass (Fig. 4C; dry weight basis), and a faster growth rate, as evident from plant height data (Fig. 4A). A faster growth rate has also been observed in barley, wherein colonized plants took 1 week less to reach flowering (Waller et al. 2008), and in the model plant A. thaliana, where plants grew faster, contained more leaves, and started to flower earlier (Peškan-Berghöfer et al. 2004) when colonized with $S$. indica. We have observed the same phenomenon in winter wheat (Craven and Ray 2017).

It is estimated that plant root hairs make up to two-thirds of the total root surface area (Vincent et al. 2017). Thus, increasing root surface area via root hair formation and elongation aids plants in absorbing nutrients and establishing relationships with microbes (Grierson and Schiefelbein 2002). We observed a significant increase in root hair density leading to an overall increase in root surface area when either of the Serendipita fungal symbionts was present in close proximity to but still not touching the host plant. A similar phenomenon was also observed in A. thaliana, where changes in the morphology of the root hairs were visible prior to root proliferation by S. indica (Peškan-Berghöfer et al. 2004). Modulation of root hair development has also been observed during AM colonization (Liu et al. 2018; Wu et al. 2016).

A variety of phytohormones such as ethylene, JA, brassinosteroids (BR), and strigolactones play pivotal roles in root-hair growth and development (Katsumi et al. 2000; Lee and Cho 2013). Serendipita colonization significantly upregulated JAZ genes, known to be involved in the regulation of JA, at the precontact stage and downregulated a sterol methyltransferase 1 gene (Pavir.8KG171400) at the postcontact stage. The latter is involved in BR biosynthesis, also suggesting a role for these fungi in modulating root hair development. In accordance with our findings, Schäfer et al. (2009b) reported the genes involved in synthesis of BR precursors to be upregulated post-S. indica inoculation.

JAZ proteins also act as repressors of JA-responsive genes when levels of JA are low (Chung et al. 2008). Accordingly, we found significant reductions in switchgrass shoot JA in both S. bescii- and $S$. vermifera-colonized plants with respect to the uninoculated control (Supplementary Fig. S3). Vahabi et al. (2015) reported an increased level of both SA and JA in Arabidopsis roots and shoots, respectively, prior to establishment of physical contact, and decreased levels of these phytohormones postcolonization with $S$. indica. We also observed increased levels of SA and decreased levels of JA in switchgrass plants at pre- and postcontact stages of $S$. bescii or $S$. vermifera colonization, albeit these were statistically insignificant (Supplementary Fig. S3).

Table 1. List of switchgrass genes described in this study that were differentially expressed at four different stages of colonization by Serendipita bescii and $S$. vermifera respectively ${ }^{\mathrm{a}}$

\begin{tabular}{|c|c|c|c|c|c|c|c|c|c|c|}
\hline \multirow[b]{3}{*}{ Gene ID } & \multicolumn{4}{|c|}{ Precontact stage } & \multicolumn{4}{|c|}{ Contact stage } & \multirow{2}{*}{\multicolumn{2}{|c|}{$\begin{array}{c}\text { Postcontact stage } \\
\text { S. vermifera }\end{array}$}} \\
\hline & \multicolumn{2}{|c|}{ S. vermifera } & \multicolumn{2}{|c|}{ S. bescii } & \multicolumn{2}{|c|}{ S. vermifera } & \multicolumn{2}{|c|}{ S. bescii } & & \\
\hline & $\log _{2} \mathrm{FC}$ & $P_{\text {adj }}$ & $\log _{2} \mathrm{FC}$ & $P_{\text {adj }}$ & $\log _{2} \mathrm{FC}$ & $P_{\text {adj }}$ & $\log _{2} \mathrm{FC}$ & $P_{\text {adj }}$ & $\log _{2} \mathrm{FC}$ & $P_{\text {adj }}$ \\
\hline Pavir.1KG232800 & 0.21 & 0.56 & 0.86 & 0.18 & -0.49 & 1 & -0.39 & 1 & 0.7 & $8.40 \mathrm{E}-15$ \\
\hline Pavir.1KG391400 & -0.2 & 1 & 0.3 & 1 & -2 & 1 & -1.9 & 1 & 5 & 0.024 \\
\hline Pavir.1KG410000 & -0.71 & 1 & -0.41 & 1 & -0.82 & 1 & -0.74 & 1 & -2 & 0.49 \\
\hline Pavir.1KG410100 & -0.91 & 1 & -0.99 & 1 & -0.59 & 1 & -0.9 & 1 & -3.1 & 0.0016 \\
\hline Pavir.1KG410200 & -0.43 & 1 & -0.94 & 1 & -0.87 & 1 & -0.6 & 1 & -3.2 & 0.00051 \\
\hline Pavir.1NG327600 & 1 & $1.30 \mathrm{E}-06$ & 2.3 & $6.20 \mathrm{E}-10$ & -0.023 & 1 & 1.1 & 1 & 2.7 & 1 \\
\hline Pavir.1NG353200 & 0.033 & 1 & 0.012 & 1 & -0.012 & 0.00017 & -0.0026 & 1 & -1 & 3.40E-08 \\
\hline Pavir.1NG545300 & 3.7 & 0.018 & -0.17 & 1 & 2.2 & 1 & 1.1 & 1 & 1.5 & 1 \\
\hline Pavir.2NG224400 & -0.0072 & 1 & 0.66 & 1 & -1.3 & $2.70 \mathrm{E}-06$ & -0.41 & 1 & -1.4 & 1 \\
\hline Pavir.5NG225300 & 0.96 & 4.70E-06 & 1.4 & 5.30E-07 & -0.038 & 1 & -0.16 & 1 & 0.98 & 1 \\
\hline Pavir.6KG167600 & 1.4 & $1.00 \mathrm{E}+00$ & -0.88 & $1.00 \mathrm{E}+00$ & 0.15 & 1 & 2 & 1 & -0.36 & 1 \\
\hline Pavir.6KG213100 & 0.52 & 1 & 6 & 0.0014 & 0.39 & 1 & 0.59 & 1 & 3.8 & 0.36 \\
\hline Pavir.6KG237100 & -1.3 & $1.60 \mathrm{E}-31$ & 2.9 & 1 & -1.1 & 1 & -0.84 & 1 & 3.2 & 1 \\
\hline Pavir.6KG259000 & 0.22 & 0.071 & 5.7 & $7.40 \mathrm{E}-13$ & -0.01 & 1 & -0.042 & 1 & 2.7 & $6.30 \mathrm{E}-85$ \\
\hline Pavir.6KG260300 & 0.81 & 1 & 5.1 & 0.013 & 0.14 & 1 & 0.047 & 1 & 3.6 & 0.55 \\
\hline Pavir.6NG319800 & 1.2 & 0.0006 & 1.3 & 0.00037 & -0.73 & 1 & -0.97 & 1 & 1.4 & 1 \\
\hline Pavir.7KG240500 & 0.59 & 1 & 1.5 & 1 & -0.74 & 1 & -0.67 & 1 & 1.9 & 6.00E-08 \\
\hline Pavir.7NG327800 & -3.5 & 0.0015 & -2.8 & 0.074 & -0.71 & 1 & 0.27 & 1 & -1.4 & 1 \\
\hline Pavir.7NG351300 & 0.21 & 1 & 1.3 & 1 & -0.45 & 1 & -0.39 & 1 & 0.94 & 0.00023 \\
\hline Pavir. $8 K G 171400$ & 0.21 & 1 & -1.5 & 1 & 0.34 & 1 & 0.14 & 1 & -2.9 & 1 \\
\hline Pavir.8KG325100 & -5.6 & 0.00053 & -2.6 & 1 & -0.053 & 1 & -0.19 & 1 & -0.8 & 1 \\
\hline Pavir.8NG064700 & -1.1 & 1 & 2 & 1 & 0.43 & 1 & 4.1 & 1 & 1.3 & 1 \\
\hline Pavir.8NG101200 & 7.5 & $5.70 E-14$ & 8.6 & 1.90E-18 & 0.86 & 1 & -0.16 & 1 & -0.11 & 1 \\
\hline Pavir.8NG213200 & -1.2 & 1 & -0.051 & 1 & 0.78 & $1.10 \mathrm{E}-05$ & 1.4 & 2.10E-06 & 0.12 & 1 \\
\hline Pavir.8NG336400 & -5.3 & 0.00055 & -2.3 & 1 & 0.57 & 1 & 0.23 & 1 & -0.98 & 1 \\
\hline Pavir.9KG268100 & 0.41 & 0.00053 & 0.27 & 0.0021 & -2.2 & 1 & -1.7 & 1 & 2.5 & 1 \\
\hline Pavir.9KG616700 & 0.19 & 0.0046 & 0.75 & $1.80 \mathrm{E}-05$ & -0.16 & 1 & -0.26 & 1 & 2.9 & 1 \\
\hline Pavir.9NG352200 & 0.29 & 0.26 & 0.96 & 0.069 & -0.5 & 1 & -0.36 & 1 & 0.86 & 7.90E-05 \\
\hline Pavir.9NG495700 & -0.84 & 1 & -1 & 1 & -0.72 & 1 & -0.76 & 1 & -3.1 & 0.0023 \\
\hline Pavir.9NG495800 & -0.74 & 1 & -1.5 & 1 & -0.6 & 1 & -0.44 & 1 & -2.9 & 0.24 \\
\hline Pavir.9NG796100 & 0.74 & 4.70E-06 & 0.44 & 5.00E-05 & -1.3 & 1 & -0.66 & 1 & 3.1 & 1 \\
\hline Pavir.J509800 & -0.89 & 1 & -0.11 & 1 & 0.55 & $5.20 \mathrm{E}-06$ & 1.1 & 1.40E-06 & 0.32 & 1 \\
\hline Pavir.J719400 & 0.5 & 0.0056 & 4.7 & $1.20 \mathrm{E}-09$ & -1.9 & 1 & -2 & 1 & 1.8 & 1 \\
\hline & & & & & & & & & (Continued & next page \\
\hline
\end{tabular}

${ }^{\mathrm{a}} \log _{2} \mathrm{FC}=\log _{2}$ fold change, $P_{\text {adj }}=$ adjusted $P$ value.

${ }^{\mathrm{b}} \mathrm{PR} 1$ = pathogenesis-related $1 ; \mathrm{CAP}=$ cysteine-rich secretory proteins, antigen 5, and PR1 protein; and NB-ARC = nucleotide-binding adaptor shared by APAF-1, resistance $(\mathrm{R})$ proteins, and CED-4. 
It has also been reported that enhanced GA biosynthesis leads to higher SA- and reduced JA-mediated defense responses (Navarro et al. 2008). Along these lines, we found that $S$. vermifera colonization upregulated a GA2ox gene in the host (Pavir.1KG391400) that catalyzes the deactivation of bioactive GA, whereas $S$. bescii downregulated a GA biosynthesis gene GA20ox (Pavir. $6 K G 167600)$ at the postcontact stage of colonization, both leading to reduced synthesis of bioactive GA. A similar trend has been observed in barley, where $S$. indica colonization led to downregulation of the GA20ox gene (Schäfer et al. 2009a). Although it remains unclear whether bioactive GA levels were actually increased or decreased in this study, our findings do indicate that GA levels are likely modulated by infection with $S$. vermifera and $S$. bescii, supporting a role for GA signaling in modifying the SA-JA balance.

Recent studies have also shown that levels of bioactive GA are negatively correlated with tillering in switchgrass and rice (Lo et al. 2008; Wuddineh et al. 2015), as well as early flowering in barley, legumes, and A. thaliana (Boden et al. 2014). In two independent studies, Kim et al. (2017) and Pan et al. (2017) demonstrated that $S$. indica promotes early flowering in A. thaliana, likely by increasing the GA content. Although we have not documented increases in tiller number at the late postcontact stage of colonization in the present study, increased tillering in winter wheat under greenhouse conditions (Craven and Ray 2017) and in switchgrass under field conditions (data not presented) is consistently observed when colonized with Serendipita fungi. Although more evidence is required to identify the exact mechanisms behind these observations, our transcriptome data suggests that Serendipita colonization may regulate the metabolism of bioactive GA, eventually leading to a faster growth rate.

\section{Reprogramming of the host defense response and carbohydrate metabolism.}

Plants can perceive microbes through the recognition of microbe-derived molecules even before the establishment of physical contact, leading to activation of plant defense responses (Cook et al. 2015; Fesel and Zuccaro 2016a). This has been observed in the closely related $S$. indica, wherein microbe recognition activated defense genes in barley (Schäfer et al. 2009b) and PR proteins in A. thaliana (Thürich et al. 2018). Similarly, our transcript data revealed upregulated genes encoding PR1 proteins in switchgrass prior to contact with the fungus, again suggesting recognition of $S$. bescii and a subsequent defense response. Similarly, both $S$. bescii and $S$. vermifera strongly upregulated genes involved in the biosynthesis of antifungal phytoalexins at the precontact stage and downregulated them at the postcontact stage. Such a trend was also observed in A. thali$a n a$, wherein $S$. indica strongly induced biosynthesis of camalexin, an $A$. thaliana-specific phytoalexin (Peskan-Berghöfer et al. 2015) upon colonization.

A third example of this expression pattern involves lignin, a highly recalcitrant plant polymer and structural component of the plant defense response against invading microbes (Miedes et al. 2014). Hence, the capacity of a fungus to decay

Table 1. (Continued from previous page)

\begin{tabular}{|c|c|c|c|c|c|c|c|}
\hline \multirow[b]{3}{*}{ Gene ID } & \multirow{2}{*}{\multicolumn{2}{|c|}{$\begin{array}{c}\text { Postcontact stage } \\
\text { S. bescii } \\
\end{array}$}} & \multicolumn{4}{|c|}{ Late precontact stage } & \multirow[b]{3}{*}{ Description $^{\text {b }}$} \\
\hline & & & \multicolumn{2}{|c|}{ S. vermifera } & \multicolumn{2}{|c|}{ S. bescii } & \\
\hline & $\log _{2} \mathrm{FC}$ & $P_{\text {adj }}$ & $\log _{2} \mathrm{FC}$ & $P_{\text {adj }}$ & $\log _{2} \mathrm{FC}$ & $P_{\text {adj }}$ & \\
\hline Pavir.1KG232800 & 0.52 & 2.10E-14 & -0.0008 & 1 & -0.0008 & 1 & Gluconeogenesis \\
\hline Pavir.1KG391400 & 1.2 & 0.81 & 0.61 & 1 & 0.61 & 0.99 & Gibberellin 2-oxidase 9 \\
\hline Pavir.1KG410000 & -2.6 & 0.042 & -0.32 & 1 & -0.32 & 0.99 & Monoterpenoid dehydrogenase \\
\hline Pavir.1KG410100 & -2.9 & 0.006 & -0.23 & 1 & -0.23 & 0.99 & Monoterpenoid dehydrogenase \\
\hline Pavir.1KG410200 & -3.4 & 0.00012 & -0.74 & 1 & -0.74 & 0.99 & Monoterpenoid dehydrogenase \\
\hline Pavir.1NG327600 & 0.33 & 0.9 & 0.7 & 1 & 0.7 & 0.99 & Laccase 14 \\
\hline Pavir.1NG353200 & -1 & 2.70E-09 & 0.55 & 1 & 0.55 & 0.99 & $\begin{array}{l}\text { Fatty acid hydroxylase superfamily:Wax } 2 \mathrm{C} \text { - } \\
\text { terminal domain-containing protein }\end{array}$ \\
\hline Pavir.1NG545300 & -0.86 & 0.81 & 1.1 & 1 & 1.1 & 1 & Sucrose synthase, putative, expressed \\
\hline Pavir.2NG224400 & 1.5 & 0.81 & -0.14 & 1 & -0.14 & 0.99 & $\begin{array}{l}\text { Hydroxycinnamoyl-CoA shikimate/quinate } \\
\text { hydroxycinnamoyl transferase }\end{array}$ \\
\hline Pavir.5NG225300 & 0.32 & 0.92 & 0.13 & 1 & 0.13 & 0.99 & Biosynthesis of phytoalexin camalexin \\
\hline Pavir.6KG167600 & -4.7 & 0.0088 & -0.84 & 1 & -0.84 & 0.99 & Gibberellin 20 oxidase 2 , putative, expressed \\
\hline Pavir.6KG213100 & 3.1 & 0.78 & 0.3 & 1 & 0.3 & 0.99 & PR1 protein \\
\hline Pavir.6KG237100 & -0.65 & 0.84 & 0.4 & 1 & 0.4 & 0.99 & Trehalose-6-phosphate synthase, putative, expressed \\
\hline Pavir.6KG259000 & 1.7 & 1.40E-77 & 1 & 1 & 1 & 0.99 & PR1 protein \\
\hline Pavir.6KG260300 & 2.1 & 0.81 & 0.32 & 1 & 0.32 & 0.99 & CAP superfamily protein \\
\hline Pavir.6NG319800 & 0.19 & 0.96 & -0.06 & 3.30E-26 & -0.06 & 1 & Glutathione S-transferase $\theta 3$ \\
\hline Pavir.7KG240500 & 1.2 & 5.60E-07 & -0.64 & 1 & -0.64 & 0.99 & $\mathrm{R}$ protein (disease resistance)-NB-ARC \\
\hline Pavir.7NG327800 & -1.8 & 0.81 & -0.51 & 1 & -0.51 & 0.99 & Gibberellin 2-oxidase 8 \\
\hline Pavir.7NG351300 & 0.42 & 0.0013 & -0.25 & 1 & -0.25 & 1 & $\mathrm{R}$ protein (disease resistance)-NB-ARC \\
\hline Pavir.8KG171400 & -4.7 & 0.049 & 2.1 & 1 & 2.1 & 1 & $\begin{array}{l}\text { Sterol methyltransferase 1: brassinosteroid } \\
\text { biosynthesis }\end{array}$ \\
\hline Pavir.8KG325100 & 0.078 & 0.98 & 0.45 & 1 & 0.45 & 0.99 & $\begin{array}{l}\mathrm{R} \text { protein, stripe rust resistance protein } \mathrm{Yr} 10 \text {, } \\
\text { putative, expressed }\end{array}$ \\
\hline Pavir.8NG064700 & -0.59 & 0.86 & 1.5 & 3.10E-30 & 1.5 & $5.20 \mathrm{E}-28$ & $\mathrm{R}$ protein (disease resistance)-NB-ARC \\
\hline Pavir.8NG101200 & -1.9 & 0.81 & 2.7 & 1 & 2.7 & 0.99 & Biosynthesis of terpenoid phytoalexins \\
\hline Pavir.8NG213200 & -0.32 & 0.89 & 0.8 & 1 & 0.8 & 0.99 & $\mathrm{R}$ protein (disease resistance)-NB-ARC \\
\hline Pavir.8NG336400 & -0.1 & 0.97 & 0.73 & 1 & 0.73 & 0.99 & $\begin{array}{l}\mathrm{R} \text { protein, stripe rust resistance protein } \mathrm{Yr} 10 \text {, } \\
\text { putative, expressed }\end{array}$ \\
\hline Pavir.9KG268100 & 1.7 & 0.81 & 1.1 & 1 & 1.1 & 1 & Jasmonate-ZIM-domain protein 11 \\
\hline Pavir.9KG616700 & 0.42 & 0.85 & 0.42 & 1 & 0.42 & 1 & Jasmonate-ZIM-domain protein 1 \\
\hline Pavir.9NG352200 & 0.58 & 0.00017 & 0.0041 & 1 & 0.0041 & 0.99 & Fructose-1,6-bisphosphatase, putative, expressed \\
\hline Pavir.9NG495700 & -3.3 & 0.00033 & 0.45 & 1 & 0.45 & 0.99 & Glutathione S-transferase family protein \\
\hline Pavir.9NG495800 & -4.1 & 0.0017 & 0.24 & 1 & 0.24 & 0.99 & Glutathione S-transferase family protein \\
\hline Pavir.9NG796100 & 1.3 & 0.81 & 0.0014 & 1 & 0.0014 & 0.99 & Jasmonate-ZIM-domain protein 1 \\
\hline Pavir.J509800 & -0.04 & 0.99 & 0.82 & 1 & 0.82 & 0.99 & $\mathrm{R}$ protein (disease resistance) \\
\hline Pavir.J719400 & 1 & 0.82 & -0.36 & 1 & -0.36 & 0.99 & Ent-kaurene synthase: gibberellin biosynthesis \\
\hline
\end{tabular}


lignocellulose could impart the potential for successful colonization (Kohler et al. 2015). Rhizoctonial orchid mycorrhizal fungi such as $S$. vermifera included in this study have been reported to produce laccase enzymes involved in plant material degradation (Basiewicz et al. 2012). Although S. indica was reported to be laccase negative on a standard plate assay (Basiewicz et al. 2012), two recent studies involving the transcriptional responses of soybean roots colonized with $S$ indica (Bajaj et al. 2018) and barley roots colonized with $S$. vermifera (Sarkar et al. 2019) suggest strong upregulation of host laccase genes. Perhaps not surprising given the results above, both $S$. bescii and $S$. vermifera led to upregulation of a host laccase gene prior to contact but inactivated it at the contact stage of colonization. These data are consistent with the hypothesis that recognition of the fungus by the plant occurs prior to contact and triggers the initiation of components of the plant defense response. Ultimately, the host response is quenched, likely facilitating colonization and the establishment of a functional symbiosis.

Finally, successful colonization by beneficial or pathogenic fungi often induces the breakdown of photosynthetically derived sucrose to meet their carbon requirements (Rolland et al. 2006; Schaarschmidt et al. 2006). Such alterations in sucrose levels are monitored by the plant Tre6P via negative feedback regulation, helping plants to maintain optimum sucrose levels (Figueroa and Lunn 2016; Meitzel et al. 2021). In this study, S. vermifera activated host sucrose synthase and Tre6P genes prior to colonization. Likewise, a similar trend was also observed in soybean, where $S$. indica colonization upregulated a host vacuolar invertase involved in sucrose hydrolysis (Bajaj et al. 2018). Finally, at later stages of colonization, $S$ bescii and $S$. vermifera both induced plant genes involved in gluconeogenesis that drive the generation of glucose from the breakdown of noncarbohydrate carbon substrates such as glucogenic amino acid and lipids. We suggest that such reprogramming of carbohydrate metabolism induced by Serendipita spp. initiates prior to contact, and sets the stage for successful colonization and functioning at later stages of symbiosis.

\section{Conclusion.}

Symbiotic microbes inducing host improvements in productivity and stress tolerance hold tremendous potential for crop production. Here, we take a step toward understanding plant symbiosis with Serendipitaceae fungi through host transcriptional profiling. We report that regulation of the switchgrass root transcriptome followed a similar pattern in response to colonization by two strains from North America and Australia; namely, $S$. bescii and $S$. vermifera, respectively. This may indicate a conserved response to members of this fungal order. Our results demonstrate that there is a clear recognition of Serendipita spp. by the host prior to contact, marked by shifts in gene expression for hormone production, defense-related responses, and carbohydrate metabolism, all important components for successful infection. Expression of plant defense genes at early stages of colonization and then damping during postcolonization may suggest stabilization of the symbiosis. Collectively, these findings suggest that Serendipita fungi are able to circumvent the host stress response machinery for the establishment of a successful symbiotic relationship.

\section{MATERIALS AND METHODS}

\section{Fungal material and culture conditions.}

$S$. bescii NFPB0129 used in this study was isolated from Noble Research Institute's switchgrass field located in Ardmore, OK, U.S.A. (Ray et al. 2018a). The S. vermifera strain MAFF305830 was obtained from the National Institute of Agrobiological Sciences, Tsukuba, Japan. The strains were routinely maintained in modified Melin Norkan's (MMN) media (Marx 1969), with $1 \%$ glucose at pH 6.0 in $24^{\circ} \mathrm{C}$.

\section{Plant material.}

Switchgrass (Panicum virgatum L.) cultivar Alamo was used in this study. Seed were briefly surface sterilized following the protocol modified after Xi et.al (2009). Briefly, seed were washed with $100 \%$ Clorox (8.25\% sodium hypochlorite; Clorox, Oakland, CA, U.S.A.) containing $0.1 \%$ Tween20 (Amresco, Solon, OH, U.S.A.) for $1 \mathrm{~h}$. After three washes with sterile water, seed were soaked in sterile water and kept at $4{ }^{\circ} \mathrm{C}$ overnight. Subsequently, seed were treated one additional time with 100\% Clorox for $30 \mathrm{~min}$, washed with sterile water three times, air dried, and germinated on agar plates in the MMN medium in vitro (Bécard and Fortin 1988; Schultze 2013).

\section{Experimental set up for transcriptome analysis.}

Inoculum of $S$. vermifera and $S$. bescii were prepared following the protocol described by Ray et al. (2018b). The germinated switchgrass seedlings were placed onto a square Petri dish containing MMN medium (Fig. 1) Agar plates were inoculated by placing a drop (approximately $10 \mu \mathrm{l}$ ) of inoculum comprising freshly ground mycelia of either $S$. vermifera or $S$. bescii approximately $5 \mathrm{~cm}$ away from the seedling. Seedlings were maintained in a TCR-180 Conviron growth chamber (Controlled Environments Ltd, Winnipeg, MB, Canada) at $24^{\circ} \mathrm{C}$ and $50 \%$ relative humidity $(\mathrm{RH})$ with a $16-\mathrm{h}$ photoperiod until the desired stage (i.e., precontact, contact, and postcontact stages) (Fig. 1). A subset of colonized seedlings from the postcontact stage and the corresponding uninoculated control plants were transplanted into 4.5-in. geranium pots (American Plant Products, Oklahoma City, OK, U.S.A.), filled with autoclaved Metro-Mix360 (SunGro Horticulture, Agawam, MA, U.S.A.) and transferred to the greenhouse $\left(26^{\circ} \mathrm{C}, 50 \% \mathrm{RH}\right.$, and 16 -h photoperiod). The seedlings were maintained for an additional 4 weeks (late postcontact stage) before harvest (Fig. 4A). Plants were watered once a week.

\section{Visualization of colonization by confocal microscopy.}

Colonization of switchgrass roots by $S$. bescii and S. vermifera at different stages of colonization was visualized by fluorescence staining and confocal microscopy (Fig. 2) following the protocol described by Ray et al. (2018b). To visualize fungal mycelia and the cell wall, roots were stained with WGA-AF 488 (Life Technologies, Carlsbad, CA, U.S.A.), followed by counter staining with propidium iodide (Biotium, Hayward, CA, U.S.A.) respectively. Stained root samples were visualized in a Leica TCS-SP8 point scanning confocal microscope (Leica Microsystems, Wetzlar, Germany) (Fig. 2).

\section{Estimation of root hair density.}

To visualize and estimate the effect of Serendipita colonization on switchgrass root architecture, root hair density and surface area were measured at the precontact stage of colonization (Fig. 3). Images of the root tip were acquired using an Olympus SZX 12 fluorescent stereomicroscope (Olympus Corporation, Tokyo, Japan) equipped with an Olympus DP-80 dual CCD color and monochrome camera, and run by Olympus cellSens image acquisition software. Subsequently, a uniform fragment of $2 \mathrm{~mm}$ was selected from the root maturation zone for the estimation of root hair density and root surface area using RhizoVision Analyzer (version 1.0.3) (Seethepalli et al. 2019). Within each colonization treatment, the data were analyzed by one-way analysis of variance using CoStat statistical software 6.4 (Cohort, Berkeley, CA, U.S.A.). Treatment means were compared using the least significant difference value at $P<0.05$. The data were plotted graphically using the package ggplot2 
(Wickham 2016) in $\mathrm{R}$ studio (R Studio, Inc., Boston, MA, U.S.A.).

\section{Estimation of plant biomass.}

Plants were harvested at late postcontact stage of colonization for the measurement of height, tiller diameter, and shoot dry biomass (Fig. 4). The data analysis and the graphical presentation follows the same procedure as for root hair density.

\section{RNA sequencing and data analysis.}

Switchgrass seedlings were harvested at pre contact, contact, postcontact (Supplementary Fig. S1), and late postcontact stage (Fig. 4). Total RNA was isolated from root tissues using an RNeasy Plant Mini Kit (Qiagen, Hilden, Germany). RNAsequencing (RNA-seq) libraries were prepared using a TruSeq Stranded mRNA sample preparation kit (Illumina, Inc., San Diego, CA, U.S.A.). mRNA was purified from $1 \mu \mathrm{g}$ of total RNA, fragmented, and reversed transcribed using random hexamers and SSII (Invitrogen) followed by second-strand synthesis. The fragmented cDNA was treated with end-pair, A-tailing, adapter ligation, and eight cycles of PCR. The prepared libraries were quantified using KAPA Biosystem's next-generation sequencing library qPCR kit and run on a Roche LightCycler 480 real-time PCR instrument. The quantified libraries were then multiplexed with other libraries, and the pool of libraries was then prepared for sequencing on the Illumina HiSeq sequencing platform utilizing a TruSeq paired-end cluster kit, $\mathrm{v} 4$, and Illumina's cBot instrument to generate a clustered flow cell for sequencing. Sequencing of the flow cell was performed on the Illumina HiSeq 2500 sequencer using HiSeq TruSeq SBS sequencing kits, v4, following a 2-by-150 indexed run recipe (Illumina). RNA-seq was conducted with three biological replicates for each treatment.

Raw fastq file reads were filtered and trimmed using BBDuk. Raw reads were evaluated for artifact sequences by k-mer matching $(\mathrm{k}-\mathrm{mer}=25)$, allowing one mismatch, and detected artifacts were trimmed from the $3^{\prime}$ end of the reads. RNA spikein reads, PhiX reads, and reads containing any Ns were removed. Quality trimming was performed using the phred trimming method set at Q6. Finally, following trimming, reads under the length threshold were removed (minimum length 25 bases or one-third of the original read length, whichever is longer). Filtered reads from each library were aligned to the switchgrass reference genome using HISAT version 0.1.4-beta (Kim et al. 2015). Differential expression testing was performed using DESeq2 (Love et al. 2014). RNA-seq data have been submitted to the DNA Data Bank of Japan/European Nucleotide Archive/ GenBank databases under accession numbers PRJNA364573 to PRJNA364575.

\section{Network analysis, distribution, and hierarchical clustering of DEGs.}

Visualization of differentially expressed switchgrass genes based on their expression data across all the stages of colonization and two fungal treatments was done in a force-directed graph to infer the relationship network using the web-based visualization tool Divenn (Sun et al. 2019). Overlapping genes between treatments are connected by two or multiple edges and the unique genes are connected by only one edge. Up- or downregulated genes were represented by red or blue nodes, respectively. The yellow node denotes genes upregulated in one treatment but downregulated in the other (Fig. 5A). Distribution of all of the genes used for the network analysis are depicted in the Venn diagram (Fig. 5B).

Hierarchical clustering (Fig. 6A) of DEGs was done to depict global changes of DEGs and to functionally categorize these DEGs across all stages of colonization by the two fungal symbionts. The heat map representation of hierarchical clustering was generated using the function heatmap. 2 in the package gplots (Warnes et al. 2016) in R studio (R Studio, Inc.) (Fig. 6A).

\section{GO enrichment analysis.}

Whole-genome GO term annotation was performed using Blast2GO (Conesa et al. 2005) with a blastp E-value hit filter of $1 \times 10^{-5}$, an annotation cutoff value of 55, and a GO weight of 5 . Using ClueGO (Bindea et al. 2009), observed GO biological processes were subjected to the right-sided hypergeometric enrichment test at medium network specificity selection and $P$ value correction was performed using the Holm-Bonferroni step-down method (Holm 1979) and visualized using Cytoscape (Shannon et al. 2003). GO term fusion and grouping settings were selected to minimize GO term redundancy, and the term enriched at the highest level of significance was used as the representative term for each functional cluster. The GO terms with $P$ values $<0.05$ were considered significantly enriched (Fig. 6B).

\section{KEGG pathway enrichment analysis of switchgrass genes.}

KEGG pathway enrichment analysis of switchgrass genes was done using KOBAS 3.0 (Xie et al. 2011) based on the inferred KEGG pathways. Enrichment analysis was done based on Fisher's exact test with FDR corrected $P$ value $<0.05$. The rich factor is calculated as the ratio of the numbers of DEGs enriched in this pathway to the numbers of all genes annotated in the same pathway. Significantly enriched pathways based on $P$ value for all of the time points were plotted graphically using the package ggplot2 (Wickham 2016) in R studio (R Studio, Inc.) (Fig. 7).

\section{Prediction of SSPs.}

To predict SSPs, we applied a comprehensive Bioinformatics pipeline that was recently used in Medicago truncatula (Boschiero et al. 2019; de Bang et al. 2017). We identified SSPs from switchgrass protein sequences from Phytozome v12.1 using the plant SSP prediction tool (Boschiero et al. 2020). Homology analyses were performed with two different algorithms and databases; namely (i) Hidden Markov model (HMM) search using the HMMER tool (Finn et al. 2011) with 4,817 HMM profiles and (ii) Smith-Waterman search using the SSearch tool (Ropelewski et al. 2003) with 3,402 known SSP genes from different plant species, including $M$. truncatula and A. thaliana, but not switchgrass. The final cumulative prediction classified three types of SSPs; namely, "known", "likely known", or "putative" SSPs (Supplementary Table S4). A known SSP has a small protein length of $\leq 200$ amino acids, SignalP D-score $>0.25$, and significant homology with previous SSPs at e-values $\leq 0.01$. A putative SSP has a protein length of $\leq 230$ amino acids, SignalP D-score $>0.45$, no presence of transmembrane helices, and no significant homologies with known SSPs or hit with one type of homology. A likely known SSP has significant homologies to known SSPs and a small protein length ( $\leq 250$ amino acids) (Supplementary Table S4; Supplementary Fig. S1).

\section{qRT-PCR validation of candidate genes.}

qRT-PCR was performed with three replicates from independent biological experiments to verify differential transcription of the candidate genes following the protocol described by Yi et al. (2009), using the QuantiTectRT-kit (Qiagen) according to the manufacturer's instruction (Supplementary Fig. S2). Real-time PCR was run on the Applied Biosystems QuantStudio 7 Flex Real Time PCR System (Applied Biosystems, Foster City, CA, U.S.A.). Normalization and comparison of mean threshold cycle (Ct) values were calculated following the method by Livak and Schmittgen (2001). To compare relative abundance of transcripts of target genes, the mean $\mathrm{Ct}$ of triplicate reactions was 
normalized by switchgrass translation elongation factor $1 \alpha$, which is one of the most stably expressed genes (Gimeno et al. 2014).

\section{Phytohormone analysis.}

The whole switchgrass were harvested at precontact, contact, and postcontact stages of colonization and frozen in liquid nitrogen. The frozen tissues were ground in liquid nitrogen to a fine powder and quickly weighed into an Eppendorf tube. The extraction was based on Almeida-Trapp et al. (2014). In brief, cold methanol/water (70:30, vol/vol) containing labeled JA and labeled SA were immediately added to the samples. The samples were vortexed and sonicated, then extracted in the cold and centrifuged at $16,000 \times g$ at $4^{\circ} \mathrm{C}$ for $5 \mathrm{~min}$. The supernatant was removed and dried with nitrogen. Each sample was redissolved in $100 \%$ methanol and the supernatant was injected into a Waters Acquity I class ultrahigh-performance liquid chromatograph (UPLC) connected to a Waters Xevo TQ-XS mass spectrometer (Waters Corp., Milford, MA, U.S.A.). Separation was carried out using a BEH C18 column $(1.76 \mu \mathrm{m}, 2.1$ by $150 \mathrm{~mm})$ (Waters Corp.) with $\mathrm{H}_{2} \mathrm{O}$ and $0.05 \%$ formic acid (solvent A) and acetonitrile and $0.05 \%$ formic acid (solvent B), starting with $5 \%$ solvent B for $1 \mathrm{~min}$, a gradient from 5 to $95 \%$ of solvent B over $4 \mathrm{~min}$, hold at $95 \%$ solvent $\mathrm{B}$ for $0.5 \mathrm{~min}$, then back to $5 \%$ solvent $\mathrm{B}$ for $3 \mathrm{~min}$ at a flow rate of $0.5 \mathrm{ml} \mathrm{min}{ }^{-1}$. The temperature of the UPLC column was set to $40^{\circ} \mathrm{C}$. The source temperature was $150^{\circ} \mathrm{C}$, desolvation gas temperature $=550^{\circ} \mathrm{C}$, desolvation gas flow $=1,000 \mathrm{ml} / \mathrm{min}$, cone gas flow $=150 \mathrm{ml} /$ $\mathrm{min}$, and nebulizer $=7 \mathrm{psi}$. Cone and collision energy were optimized for each compound individually and they were all analyzed in the negative ion mode. The selected reaction monitoring (SRM) analysis conditions for JA were as follows: capillary $=500 \mathrm{~V}$, cone voltage $=5 \mathrm{~V}$, collision energy $=14 \mathrm{~V}$, dwell time $=0.033 \mathrm{~s}$, and SRM transition $(\mathrm{m} / \mathrm{z})=209 / 59$. For d5JA, capillary $=500 \mathrm{~V}$, cone voltage $=8 \mathrm{~V}$, collision energy $=$ $12 \mathrm{~V}$, dwell time $=0.033 \mathrm{~s}$, and SRM transition $(\mathrm{m} / \mathrm{z})=214 / 61$. The SRM analysis conditions for SA were as follows: capillary = $500 \mathrm{~V}$, cone voltage $=4 \mathrm{~V}$, collision energy $=14 \mathrm{~V}$, dwell time $=0.033 \mathrm{~s}$, and SRM transition $(\mathrm{m} / \mathrm{z})=137 / 93$. For d6SA, capillary $=500 \mathrm{~V}$, cone voltage $=4 \mathrm{~V}$, collision energy $=14 \mathrm{~V}$, dwell time $=0.033 \mathrm{~s}$, and SRM transition $(\mathrm{m} / \mathrm{z})=141 / 97$. TargetLynx XS software, version 4.2, was used to quantify peak area and the amounts of JA and SA were based on comparison with the labeled hormone. The data analysis and the graphical presentation followed the same procedure as described for root hair density (Supplementary Fig. S3).

\section{Estimation of relative abundance of Serendipitaceae fungi in planta.}

The relative abundance of $S$. vermifera and $S$. bescii in switchgrass roots at different stages of colonization was estimated by qPCR (Ray et al. 2021). An actin coding gene from the switchgrass and the two fungal symbionts-namely, switchgrass ACT2 (Pavir.5NG326000), S. bescii ACT1 (sbACT1, gm1.8435_g), and $S$. vermifera ACT1 (svACT1, gm1.5972_g) -were used as indicators for calculation of relative abundance (Supplementary Table S5). Based on the haploid genome size of each organism (switchgrass $=1.12 \mathrm{~Gb}, S$. bescii $=36.9 \mathrm{Mb}$, and $S$. vermifera $=$ $38.1 \mathrm{Mb}$ ) (Lovell et al. 2021; Ray et al. 2018a) and their ploidy as well as karyotype and C value (Dolezel et al. 2003), we calculated that 2 ng of their genomic DNA (gDNA) contains 815 and approximately 26,430 copies of the ACT gene template in switchgrass and the fungi, respectively. A dilution series of fungal gDNA $(2,1.6,1.2,0.8,0.4$, and $0.0 \mathrm{ng})$ was prepared by mixing each with a dilution series of the plant gDNA (4, 4.4, 4.8, 5.2, 5.6 , and $6 \mathrm{ng}$ ) to maintain the total gDNA concentration to $6 \mathrm{ng}$ per $10 \mu \mathrm{l}$ in qPCR. Based on the above calculation, the $\mathrm{Ct}$ values were measured to generate standard curves: $S$. bescii/switchgrass template ratio $(\%)=8.66 \times 2^{-\Delta \mathrm{Ct}}, R^{2}=0.9929$ and $S$. vermiferal switchgrass template ratio $(\%)=28.98 \times 2^{-\Delta \mathrm{Ct}}, R^{2}=0.9987$ (Supplementary Fig. S4). Finally, the relative abundance of Serendipitaceae fungi in planta was quantified by using these standard curves from the $\Delta \mathrm{Ct}$ value of the root DNA (Supplementary Fig. S4).

\section{ACKNOWLEDGMENTS}

We thank A. Seethepalli for root data acquisition, M. Yi and J. Kolape for confocal microscopy, and A. Hammon for greenhouse assistance.

\section{AUTHOR-RECOMMENDED INTERNET RESOURCES}

BBDuk: https://jgi.doe.gov/data-and-tools/bbtools/bb-tools-user-guide Phytozome v12.1: https://phytozome.jgi.doe.gov/pz/portal.html

\section{LITERATURE CITED}

Ali, S., Ganai, B. A., Kamili, A. N., Bhat, A. A., Mir, Z. A., Bhat, J. A., Tyagi, A., Islam, S. T., Mushtaq, M., Yadav, P., Rawat, S., and Grover, A. 2018. Pathogenesis-related proteins and peptides as promising tools for engineering plants with multiple stress tolerance. Microbiol. Res. 212-213:29-37.

Almeida-Trapp, M., De Souza, G. D., Rodrigues-Filho, E., Boland, W., and Mithöfer, A. 2014. Validated method for phytohormone quantification in plants. Front. Plant Sci. 5:417

Bajaj, R., Huang, Y., Gebrechristos, S., Mikolajczyk, B., Brown, H., Prasad, R., Varma, A., and Bushley, K. E. 2018. Transcriptional responses of soybean roots to colonization with the root endophytic fungus Piriformospora indica reveals altered phenylpropanoid and secondary metabolism. Sci. Rep. 8:10227.

Basiewicz, M., Weiß, M., Kogel, K.-H., Langen, G., Zorn, H., and Zuccaro, A. 2012. Molecular and phenotypic characterization of Sebacina vermifera strains associated with orchids, and the description of Piriformospora williamsii sp. nov. Fungal Biol. 116:204-213.

Bécard, G., and Fortin, J. A. 1988. Early events of vesicular-arbuscular mycorrhiza formation on Ri T-DNA transformed roots. New Phytol. 108:211-218.

Begum, N., Afzal, S., Zhao, H., Lou, L., and Cai, Q. 2018. Shoot endophytic plant growth-promoting bacteria reduce cadmium toxicity and enhance switchgrass (Panicum virgatum L.) biomass. Acta Physiol. Plant. 40:170.

Bindea, G., Mlecnik, B., Hackl, H., Charoentong, P., Tosolini, M., Kirilovsky, A., Fridman, W.-H., Pagès, F., Trajanoski, Z., and Galon, J. 2009. ClueGO: A Cytoscape plug-in to decipher functionally grouped gene ontology and pathway annotation networks. Bioinformatics 25:1091-1093.

Boden, S. A., Weiss, D., Ross, J. J., Davies, N. W., Trevaskis, B., Chandler, P. M., and Swain, S. M. 2014. EARLY FLOWERING3 regulates flowering in spring barley by mediating gibberellin production and FLOWERING LOCUS T expression. Plant Cell 26:1557-1569.

Bonfante, P., and Genre, A. 2010. Mechanisms underlying beneficial plant-fungus interactions in mycorrhizal symbiosis. Nat. Commun. 1:48

Boschiero, C., Dai, X., Lundquist, P. K., Roy, S., Christian de Bang, T., Zhang, S., Zhuang, Z., Torres-Jerez, I., Udvardi, M. K., Scheible, W.-R., and Zhao, P. X. 2020. MtSSPdb: The Medicago truncatula Small Secreted Peptide Database. Plant Physiol. 183:399-413.

Boschiero, C., Lundquist, P. K., Roy, S., Dai, X., Zhao, P. X., and Scheible, W. R. 2019. Identification and functional investigation of genome-encoded, small, secreted peptides in plants. Curr. Protoc. Plant Biol. 4:e20098.

Chung, H. S., Koo, A. J., Gao, X., Jayanty, S., Thines, B., Jones, A. D. and Howe, G. A. 2008. Regulation and function of Arabidopsis JASMONATE ZIM-domain genes in response to wounding and herbivory. Plant Physiol. 146:952-964.

Conesa, A., Götz, S., García-Gómez, J. M., Terol, J., Talón, M., and Robles, M. 2005. Blast2GO: A universal tool for annotation, visualization and analysis in functional genomics research. Bioinformatics 21: 3674-3676.

Cook, D. E., Mesarich, C. H., and Thomma, B. P. 2015. Understanding plant immunity as a surveillance system to detect invasion. Annu. Rev. Phytopathol. 53:541-563. 
Craven, K., and Ray, P. 2017. Symbiont for enhancement of plant performance. U.S. Patent Application 15/626,926.

de Bang, T. C., Lundquist, P. K., Dai, X., Boschiero, C., Zhuang, Z., Pant, P., Torres-Jerez, I., Roy, S., Nogales, J., Veerappan, V., Dickstein, R., Udvardi, M. K., Zhao, P. X., and Scheible, W. R. 2017. Genome-wide identification of Medicago peptides involved in macronutrient responses and nodulation. Plant Physiol. 175:1669-1689.

Dolezel, J., Bartos, J., Voglmayr, H., and Greilhuber, J. 2003. Nuclear DNA content and genome size of trout and human. Cytometry, Part A 51A:127-128.

Fesel, P. H., and Zuccaro, A. 2016a. $\beta$-glucan: Crucial component of the fungal cell wall and elusive MAMP in plants. Fungal Genet. Biol. 90: 53-60.

Fesel, P. H., and Zuccaro, A. 2016b. Dissecting endophytic lifestyle along the parasitism/mutualism continuum in Arabidopsis. Curr. Opin. Microbiol. 32:103-112.

Figueroa, C. M., and Lunn, J. E. 2016. A tale of two sugars: Trehalose 6-phosphate and sucrose. Plant Physiol. 172:7-27.

Finn, R. D., Clements, J., and Eddy, S. R. 2011. HMMER web server: Interactive sequence similarity searching. Nucleic Acids Res. 39:W29W37.

Ghimire, S. R., Charlton, N. D., and Craven, K. D. 2009. The mycorrhizal fungus, Sebacina vermifera, enhances seed germination and biomass production in switchgrass (Panicum virgatum L). BioEnergy Res. 2:51-58

Ghimire, S. R., and Craven, K. D. 2011. Enhancement of switchgrass (Panicum virgatum L.) biomass production under drought conditions by the ectomycorrhizal fungus Sebacina vermifera. Appl. Environ. Microbiol. 77:7063-7067.

Giesemann, P., Rasmussen, H. N., Liebel, H. T., and Gebauer, G. 2020. Discreet heterotrophs: Green plants that receive fungal carbon through Paris-type arbuscular mycorrhiza. New Phytol. 226:960-966.

Gimeno, J., Eattock, N., Van Deynze, A., and Blumwald, E. 2014. Selection and validation of reference genes for gene expression analysis in switchgrass (Panicum virgatum) using quantitative real-time RT-PCR. PLoS One 9:e91474.

Grierson, C., and Schiefelbein, J. 2002. Root hairs. Arabidopsis Book 1: $\mathrm{e} 0060$.

Gullner, G., Komives, T., Király, L., and Schröder, P. 2018. Glutathione S-transferase enzymes in plant-pathogen interactions. Front. Plant Sci. 9:1836.

Hestrin, R., Kan, M., Ray, P., Stuart, R., Hawkes, C. V., Craven, K. D., Firestone, M., Nuccio, E., and Pett-Ridge, J. 2020. Beneficial Partners: Mycorrhizal Resource Exchange in Bioenergy Cropping Systems. In: Genomic Sci. Program Annu. Principal Investigator Meeting, Washington, DC

Holm, S. 1979. A simple sequentially rejective multiple test procedure. Scand. J. Stat. 6:65-70.

Inada, N., and Savory, E. A. 2011. Inhibition of prepenetration processes of the powdery mildew Golovinomyces orontii on host inflorescence stems is reduced in the Arabidopsis cuticular mutant cer3 but not in cer1. J. Gen. Plant Pathol. 77:273-281.

Karunanithi, P. S., and Zerbe, P. 2019. Terpene synthases as metabolic gatekeepers in the evolution of plant terpenoid chemical diversity. Front. Plant Sci. 10:1166.

Katsumi, M., Izumo, M., and Ridge, R. W. 2000. Hormonal control of root hair growth and development. Pages 101-114 in: Root Hairs. R. W. Ridge and A. M. C. Emons, eds. Springer, Tokyo, Japan.

Kennedy, A. H., Taylor, D. L., and Watson, L. E. 2011. Mycorrhizal specificity in the fully mycoheterotrophic Hexalectris Raf. (Orchidaceae: Epidendroideae). Mol. Ecol. 20:1303-1316.

Kim, D., Abdelaziz, M. E., Ntui, V. O., Guo, X., and Al-Babili, S. 2017. Colonization by the endophyte Piriformospora indica leads to early flowering in Arabidopsis thaliana likely by triggering gibberellin biosynthesis. Biochem. Biophys. Res. Commun. 490:1162-1167.

Kim, D., Langmead, B., and Salzberg, S. L. 2015. HISAT: A fast spliced aligner with low memory requirements. Nat. Methods 12:357-360.

Kim, S., Lowman, S., Hou, G., Nowak, J., Flinn, B., and Mei, C. 2012. Growth promotion and colonization of switchgrass (Panicum virgatum) cv. Alamo by bacterial endophyte Burkholderia phytofirmans strain PsJN. Biotechnol. Biofuels 5:37.

Kohler, A., Kuo, A., Nagy, L. G., Morin, E., Barry, K. W., Buscot, F., Canbäck, B., Choi, C., Cichocki, N., Clum, A., Colpaert, J., Copeland, A., Costa, M. D., Doré, J., Floudas, D., Gay, G., Girlanda, M., Henrissat, B., Herrmann, S., Hess, J., Högberg, N., Johansson, T., Khouja, H. R., LaButti, K., Lahrmann, U., Levasseur, A., Lindquist, E. A., Lipzen, A., Marmeisse, R., Martino, E., Murat, C., Ngan, C. Y., Nehls, U., Plett, J. M., Pringle, A., Ohm, R. A., Perotto, S., Peter, M.,
Riley, R., Rineau, F., Ruytinx, J., Salamov, A., Shah, F., Sun, H., Tarkka, M., Tritt, A., Veneault-Fourrey, C., Zuccaro, A., Tunlid, A., Grigoriev, I. V., Hibbett, D. S., Martin, F. and Mycorrhizal Genomics Initiative Consortium. 2015. Convergent losses of decay mechanisms and rapid turnover of symbiosis genes in mycorrhizal mutualists. Nat. Genet. 47:410-415.

Kuga, Y., Sakamoto, N., and Yurimoto, H. 2014. Stable isotope cellular imaging reveals that both live and degenerating fungal pelotons transfer carbon and nitrogen to orchid protocorms. New Phytol. 202:594605.

Lahrmann, U., Ding, Y., Banhara, A., Rath, M., Hajirezaei, M. R., Döhlemann, S., von Wirén, N., Parniske, M., and Zuccaro, A. 2013. Host-related metabolic cues affect colonization strategies of a root endophyte. Proc. Natl. Acad. Sci. U.S.A. 110:13965-13970.

Lahrmann, U., Strehmel, N., Langen, G., Frerigmann, H., Leson, L., Ding, Y., Scheel, D., Herklotz, S., Hilbert, M., and Zuccaro, A. 2015. Mutualistic root endophytism is not associated with the reduction of saprotrophic traits and requires a noncompromised plant innate immunity. New Phytol. 207:841-857.

Lee, R. D.-W., and Cho, H.-T. 2013. Auxin, the organizer of the hormonal/environmental signals for root hair growth. Front. Plant Sci. 4: 448.

Liu, C.-Y., Zhang, F., Zhang, D.-J., Srivastava, A. K., Wu, Q.-S., and Zou, Y.-N. 2018. Mycorrhiza stimulates root-hair growth and IAA synthesis and transport in trifoliate orange under drought stress. Sci. Rep. 8:1978.

Livak, K. J., and Schmittgen, T. D. 2001. Analysis of relative gene expression data using real-time quantitative PCR and the $2^{-\Delta \Delta C T}$ method. Methods 25:402-408.

Lo, S.-F., Yang, S.-Y., Chen, K.-T., Hsing, Y.-I., Zeevaart, J. A., Chen, L.-J., and Yu, S.-M. 2008. A novel class of gibberellin 2-oxidases control semidwarfism, tillering, and root development in rice. Plant Cell 20:2603-2618.

Love, M. I., Huber, W., and Anders, S. 2014. Moderated estimation of fold change and dispersion for RNA-seq data with DESeq2. Genome Biol. 15:550

Lovell, J. T., MacQueen, A. H., Mamidi, S., Bonnette, J., Jenkins, J., Napier, J. D., Sreedasyam, A., Healey, A., Session, A., Shu, S., Barry, K., Bonos, S., Boston, L., Daum, C., Deshpande, S., Ewing, A., Grabowski, P. P., Haque, T., Harrison, M., Jiang, J., Kudrna, D., Lipzen, A., Pendergast, T. H., IV, Plott, C., Qi, P., Saski, C. A., Shakirov, E. V., Sims, D., Sharma, M., Sharma, R., Stewart, A., Singan, V. R., Tang, Y., Thibivillier, S., Webber, J., Weng, X., Williams, M., Wu, G. A., Yoshinaga, Y., Zane, M., Zhang, L., Xhang, J., Behrman, K. D., Boe, A. R., Fay, P. A., Fritschi, F. B., Jastrow, J. D., Lloyd-Reilley, J., Martínez-Reyna, J. M., Matamala, R., Mitchell, R. B., Rouquette, F. M., Jr., Ronald, P., Saha, M., Tobias, C. M., Udvardi, M., Wing, R. A., Wu, Y., Bartley, L. E., Casler, M., Devos, K. M., Lowry, D. B., Rokhsar, D. S., Grimwood, J., Juenger, T. E., and Schmutz, J. 2021. Genomic mechanisms of climate adaptation in polyploid bioenergy switchgrass. Nature 590:438-444.

Marx, D. H. 1969. The influence of ectotrophic mycorrhizal fungi on the resistance of pine roots to pathogenic infections. I. Antagonism of mycorrhizal fungi to root pathogenic fungi and soil bacteria. Phytopathology 59:153-163.

McLaughlin, S. B., and Adams Kszos, L. 2005. Development of switchgrass (Panicum virgatum) as a bioenergy feedstock in the United States. Biomass Bioenergy 28:515-535.

Meitzel, T., Radchuk, R., McAdam, E. L., Thormählen, I., Feil, R., Munz, E., Hilo, A., Geigenberger, P., Ross, J. J., Lunn, J. E., and Borisjuk, L. 2021. Trehalose 6-phosphate promotes seed filling by activating auxin biosynthesis. New Phytol. 229:1553-1565.

Miedes, E., Vanholme, R., Boerjan, W., and Molina, A. 2014. The role of the secondary cell wall in plant resistance to pathogens. Front. Plant Sci. 5:358.

Murray, J. D., Cousins, D. R., Jackson, K. J., and Liu, C. 2013. Signaling at the root surface: The role of cutin monomers in mycorrhization. Mol. Plant 6:1381-1383.

Nakamura, S., Suzuki, T., Kawamukai, M., and Nakagawa, T. 2012. Expression analysis of Arabidopsis thaliana small secreted protein genes. Biosci. Biotechnol. Biochem. 76:436-446.

Navarro, L., Bari, R., Achard, P., Lisón, P., Nemri, A., Harberd, N. P., and Jones, J. D. G. 2008. DELLAs control plant immune responses by modulating the balance of jasmonic acid and salicylic acid signaling. Curr. Biol. 18:650-655.

Oberwinkler, F., Riess, K., Bauer, R., and Garnica, S. 2014. Morphology and molecules: The Sebacinales, a case study. Mycol. Prog. 13:445470 . 
Pan, R., Xu, L., Wei, Q., Wu, C., Tang, W., Oelmüller, R., and Zhang, W. 2017. Piriformospora indica promotes early flowering in Arabidopsis through regulation of the photoperiod and gibberellin pathways. PLoS One 12:e189791.

Parniske, M. 2008. Arbuscular mycorrhiza: The mother of plant root endosymbioses. Nat. Rev. Microbiol. 6:763-775.

Perlack, R. D. 2005. Biomass as Feedstock for a Bioenergy and Bioproducts Industry: The Technical Feasibility of a Billion-Ton Annual Supply. Oak Ridge National Laboratory, Oak Ridge, TN, U.S.A.

Peškan-Berghöfer, T., Shahollari, B., Giong, P. H., Hehl, S., Markert, C., Blanke, V., Kost, G., Varma, A., and Oelmüller, R. 2004. Association of Piriformospora indica with Arabidopsis thaliana roots represents a novel system to study beneficial plant-microbe interactions and involves early plant protein modifications in the endoplasmic reticulum and at the plasma membrane. Physiol. Plant. 122:465-477.

Peskan-Berghöfer, T., Vilches-Barro, A., Müller, T. M., Glawischnig, E., Reichelt, M., Gershenzon, J., and Rausch, T. 2015. Sustained exposure to abscisic acid enhances the colonization potential of the mutualist fungus Piriformospora indica on Arabidopsis thaliana roots. New Phytol. 208:873-886.

Ponnu, J., Wahl, V., and Schmid, M. 2011. Trehalose-6-phosphate: Connecting plant metabolism and development. Front. Plant Sci. 2:70.

Ray, P., Abraham, P. E., Guo, Y., Giannone, R. J., Engle, N. L., Yang, Z. K., Jacobson, D., Hettich, R. L., Tschaplinski, T. J., and Craven, K. D. 2019. Scavenging organic nitrogen and remodeling lipid metabolism are key survival strategies adopted by the endophytic fungi, Serendipita vermifera and Serendipita bescii to alleviate nitrogen and phosphorous starvation in vitro. Environ. Microbiol. Rep. 11:548-557.

Ray, P., Chi, M.-H., Guo, Y., Chen, C., Adam, C., Kuo, A., LaButti, K., Lipzen, A., Barry, K. W., Grigoriev, I. V., Tang, Y., and Craven, K. D. 2018a. Genome sequence of the plant growth-promoting fungus Serendipita vermifera subsp. bescii: The first native strain from North America. Phytobiomes J. 2:62-63.

Ray, P., and Craven, K. D. 2016. Sebacina vermifera: A unique root symbiont with vast agronomic potential. World J. Microbiol. Biotechnol. 32:16.

Ray, P., Guo, Y., Chi, M.-H., Krom, N., Saha, M. C., and Craven, K. D. 2021. Serendipita bescii promotes winter wheat growth and modulates the host root transcriptome under phosphorus and nitrogen starvation. Environ. Microbiol. 23:1876-1888.

Ray, P., Guo, Y., Kolape, J., and Craven, K. D. 2018b. Non-targeted colonization by the endomycorrhizal fungus, Serendipita vermifera, in three weeds typically co-occurring with switchgrass. Front. Plant Sci. 8:2236.

Ray, P., Ishiga, T., Decker, S. R., Turner, G. B., and Craven, K. D. 2015. A novel delivery system for the root symbiotic fungus, Sebacina vermifera, and consequent biomass enhancement of low lignin COMT switchgrass lines. BioEnergy Res. 8:922-933.

Riess, K., Oberwinkler, F., Bauer, R., and Garnica, S. 2014. Communities of endophytic sebacinales associated with roots of herbaceous plants in agricultural and grassland ecosystems are dominated by Serendipita herbamans sp. nov. PLoS One 9:e94676.

Rolland, F., Baena-Gonzalez, E., and Sheen, J. 2006. Sugar sensing and signaling in plants: Conserved and novel mechanisms. Annu. Rev. Plant Biol. 57:675-709

Ropelewski, A. J., Nicholas, H. B., Jr., and Deerfield, D. W., II. 2003. Mathematically complete nucleotide and protein sequence searching using Ssearch. Curr. Protoc. Bioinf. 3.10.

Sarkar, D., Rovenich, H., Jeena, G., Nizam, S., Tissier, A., Balcke, G. U., Mahdi, L. K., Bonkowski, M., Langen, G., and Zuccaro, A. 2019. The inconspicuous gatekeeper: Endophytic Serendipita vermifera acts as extended plant protection barrier in the rhizosphere. New Phytol. 224:886-901.

Schaarschmidt, S., Roitsch, T., and Hause, B. 2006. Arbuscular mycorrhiza induces gene expression of the apoplastic invertase LIN6 in tomato (Lycopersicon esculentum) roots. J. Exp. Bot. 57:4015-4023.

Schäfer, P., Pfiffi, S., Voll, L. M., Zajic, D., Chandler, P. M., Waller, F., Scholz, U., Pons-Kühnemann, J., Sonnewald, S., Sonnewald, U., and Kogel, K.-H. 2009a. Phytohormones in plant root-Piriformospora indica mutualism. Plant Signal. Behav. 4:669-671.

Schäfer, P., Pfiffi, S., Voll, L. M., Zajic, D., Chandler, P. M., Waller, F., Scholz, U., Pons-Kühnemann, J., Sonnewald, S., Sonnewald, U., and Kogel, K. H. 2009b. Manipulation of plant innate immunity and gibberellin as factor of compatibility in the mutualistic association of barley roots with Piriformospora indica. Plant J. 59:461-474.

Schmer, M. R., Vogel, K. P., Mitchell, R. B., and Perrin, R. K. 2008. Net energy of cellulosic ethanol from switchgrass. Proc. Natl. Acad. Sci. U.S.A. 105:464-469.
Schultze, M. 2013. Protocols for growing plant symbioses; Mycorrhiza Pages 47-59 in: Plant Mineral Nutrients. F. Maathuis, ed. Methods in Molecular Biology (Methods and Protocols), vol. 953. Humana Press, Totowa, NJ, U.S.A.

Seethepalli, A., Guo, H., Liu, X., Griffiths, M., Almtarfi, H., Li, Z., Liu S., Zare, A., Fritschi, F. B., Blancaflor, E. B., Ma, X.-F., and York, L. M. 2019. RhizoVision Crown: An integrated hardware and software platform for root crown phenotyping. bioRxiv. https://www.biorxiv. org/content/10.1101/569707v2

Selosse, M. A., Setaro, S., Glatard, F., Richard, F., Urcelay, C., and Weiß, M. 2007. Sebacinales are common mycorrhizal associates of Ericaceae. New Phytol. 174:864-878.

Serfling, A., Wirsel, S. G., Lind, V., and Deising, H. B. 2007. Performance of the biocontrol fungus Piriformospora indica on wheat under greenhouse and field conditions. Phytopathology 97:523-531.

Shah, F., Rineau, F., Canbäck, B., Johansson, T., and Tunlid, A. 2013. The molecular components of the extracellular protein-degradation pathways of the ectomycorrhizal fungus Paxillus involutus. New Phytol. $200: 875-887$.

Shannon, P., Markiel, A., Ozier, O., Baliga, N. S., Wang, J. T., Ramage, D., Amin, N., Schwikowski, B., and Ideker, T. 2003. Cytoscape: A software environment for integrated models of biomolecular interaction networks. Genome Res. 13:2498-2504.

Sherameti, I., Shahollari, B., Venus, Y., Altschmied, L., Varma, A., and Oelmüller, R. 2005. The endophytic fungus Piriformospora indica stimulates the expression of nitrate reductase and the starch-degrading enzyme glucan-water dikinase in tobacco and Arabidopsis roots through a homeodomain transcription factor that binds to a conserved motif in their promoters. J. Biol. Chem. 280:26241-26247.

Singh, B., and Sharma, R. A. 2015. Plant terpenes: Defense responses, phylogenetic analysis, regulation and clinical applications. 3 Biotech 5:129-151.

Sun, C.-H., Yang, C.-Y., and Tzen, J. T. C. 2018. Molecular identification and characterization of hydroxycinnamoyl transferase in tea plants (Camellia sinensis L.). Int. J. Mol. Sci. 19:3938.

Sun, L., Dong, S., Ge, Y., Fonseca, J. P., Robinson, Z. T., Mysore, K. S., and Mehta, P. 2019. DiVenn: An interactive and integrated Web-based visualization tool for comparing gene lists. Front. Genet. 10:421.

Thürich, J., Meichsner, D., Furch, A. C. U., Pfalz, J., Krüger, T., Kniemeyer, O., Brakhage, A., and Oelmüller, R. 2018. Arabidopsis thaliana responds to colonisation of Piriformospora indica by secretion of symbiosis-specific proteins. PLoS One 13:e0209658.

Turner, G. W., and Croteau, R. 2004. Organization of monoterpene biosynthesis in Mentha. Immunocytochemical localizations of geranyl diphosphate synthase, limonene-6-hydroxylase, isopiperitenol dehydrogenase, and pulegone reductase. Plant Physiol. 136:4215-4227.

Vahabi, K., Sherameti, I., Bakshi, M., Mrozinska, A., Ludwig, A. Reichelt, M., and Oelmüller, R. 2015. The interaction of Arabidopsis with Piriformospora indica shifts from initial transient stress induced by fungus-released chemical mediators to a mutualistic interaction after physical contact of the two symbionts. BMC Plant Biol. 15:58

Vance, C., Kirk, T., and Sherwood, R. 1980. Lignification as a mechanism of disease resistance. Annu. Rev. Phytopathol. 18:259-288.

Varma, A., Savita, V., Sudha, Sahay, N., Butehorn, B., and Franken, P. 1999. Piriformospora indica, a cultivable plant-growth-promoting root endophyte. Appl. Environ. Microbiol. 65:2741-2744.

Vincent, C., Rowland, D., Na, C., and Schaffer, B. 2017. A highthroughput method to quantify root hair area in digital images taken in situ. Plant Soil 412:61-80.

Vohník, M., Pánek, M., Fehrer, J., and Selosse, M.-A. 2016. Experimental evidence of ericoid mycorrhizal potential within Serendipitaceae (Sebacinales). Mycorrhiza 26:831-846.

Vohník, M., Sadowsky, J. J., Kohout, P., Lhotáková, Z., Nestby, R., and Kolařík, M. 2012. Novel root-fungus symbiosis in Ericaceae: Sheathed ericoid mycorrhiza formed by a hitherto undescribed basidiomycete with affinities to Trechisporales. PLoS One 7:e39524.

Waller, F., Achatz, B., Baltruschat, H., Fodor, J., Becker, K., Fischer, M., Heier, T., Hückelhoven, R., Neumann, C., von Wettstein, D., Franken, P., and Kogel, K. H. 2005. The endophytic fungus Piriformospora indica reprograms barley to salt-stress tolerance, disease resistance, and higher yield. Proc. Natl. Acad. Sci. U.S.A. 102:13386-13391.

Waller, F., Mukherjee, K., Deshmukh, S. D., Achatz, B., Sharma, M., Schäfer, P., and Kogel, K.-H. 2008. Systemic and local modulation of plant responses by Piriformospora indica and related Sebacinales species. J. Plant Physiol. 165:60-70.

Wang, E., Schornack, S., Marsh, J. F., Gobbato, E., Schwessinger, B., Eastmond, P., Schultze, M., Kamoun, S., and Oldroyd, G. E. 2012. A 
common signaling process that promotes mycorrhizal and oomycete colonization of plants. Curr. Biol. 22:2242-2246.

Warcup, J., and Talbot, P. 1967. Perfect states of Rhizoctonias associated with orchids. New Phytol. 66:631-641.

Warnes, G. R., Bolker, B., Bonebakker, L., Gentleman, R., Liaw, W. H. A., Lumley, T., Maechler, M., Magnusson, A., Moeller, S., and Schwartz, M. 2016. gplots: Various R programming tools for plotting data. $\mathrm{R}$ package version 3.0. 1. The Comprehensive $\mathrm{R}$ Archive Network. https://rdrr.io/cran/gplots/

Weiß, M., Sýkorová, Z., Garnica, S., Riess, K., Martos, F., Krause, C., Oberwinkler, F., Bauer, R., and Redecker, D. 2011. Sebacinales everywhere: Previously overlooked ubiquitous fungal endophytes. PLoS One 6:e16793.

Weiß, M., Waller, F., Zuccaro, A., and Selosse, M. A. 2016. Sebacinales-One thousand and one interactions with land plants. New Phytol. 211:20-40.

Wickham, H. 2016. ggplot2: Elegant graphics for data analysis. Springer. https://ggplot2-book.org/

Wipf, D., Krajinski, F., van Tuinen, D., Recorbet, G., and Courty, P. E. 2019. Trading on the arbuscular mycorrhiza market: From arbuscules to common mycorrhizal networks. New Phytol. 223:1127-1142.

Wu, Q.-S., Liu, C.-Y., Zhang, D.-J., Zou, Y.-N., He, X.-H., and Wu, Q.H. 2016. Mycorrhiza alters the profile of root hairs in trifoliate orange. Mycorrhiza 26:237-247.

Wuddineh, W. A., Mazarei, M., Zhang, J., Poovaiah, C. R., Mann, D. G., Ziebell, A., Sykes, R. W., Davis, M. F., Udvardi, M. K., and Stewart, C. N., Jr. 2015. Identification and overexpression of gibberellin 2-oxidase (GA2ox) in switchgrass (Panicum virgatum L.) for improved plant architecture and reduced biomass recalcitrance. Plant Biotechnol. J. 13:636-647.
Xi, Y., Fu, C., Ge, Y., Nandakumar, R., Hisano, H., Bouton, J., and Wang, Z.-Y. 2009. Agrobacterium-mediated transformation of switchgrass and inheritance of the transgenes. BioEnergy Res. 2:275283.

Xie, C., Mao, X., Huang, J., Ding, Y., Wu, J., Dong, S., Kong, L., Gao, G., Li, C.-Y., and Wei, L. 2011. KOBAS 2.0: A web server for annotation and identification of enriched pathways and diseases. Nucleic Acids Res. 39:W316-W322.

Yadav, V., Kumar, M., Deep, D. K., Kumar, H., Sharma, R., Tripathi, T., Tuteja, N., Saxena, A. K., and Johri, A. K. 2010. A phosphate transporter from the root endophytic fungus Piriformospora indica plays a role in the phosphate transport to the host plant. (This article has been withdrawn) J. Biol. Chem. 285:26532-26544.

Yamaguchi, S. 2008. Gibberellin metabolism and its regulation. Annu. Rev. Plant Biol. 59:225-251.

Yamamoto, T., Miura, C., Fuji, M., Nagata, S., Otani, Y., Yagame, T., Yamato, M., and Kaminaka, H. 2017. Quantitative evaluation of protocorm growth and fungal colonization in Bletilla striata (Orchidaceae) reveals less-productive symbiosis with a non-native symbiotic fungus. BMC Plant Biol. 17:50.

Yi, M., Chi, M.-H., Khang, C. H., Park, S.-Y., Kang, S., Valent, B., and Lee, Y.-H. 2009. The ER chaperone LHS1 is involved in asexual development and rice infection by the blast fungus Magnaporthe oryzae. Plant Cell 21:681-695.

Zhang, Y., Wu, L., Wang, X., Chen, B., Zhao, J., Cui, J., Li, Z., Yang, J., Wu, L., Wu, J., Zhang, G., and Ma, Z. 2019. The cotton laccase gene GhLAC15 enhances Verticillium wilt resistance via an increase in defence-induced lignification and lignin components in the cell walls of plants. Mol. Plant Pathol. 20:309-322. 